\title{
Effects of Ternary Additions on the Microstructure and Thermal Stability of Directionally-Solidified $\mathrm{MoSi}_{2} / \mathrm{Mo}_{5} \mathrm{Si}_{3}$ Eutectic Composites
}

Kosuke Fujiwara ${ }^{1}$, Hirotaka Matsunoshita ${ }^{1}$, Yuta Sasai ${ }^{1}$, Kyosuke Kishida ${ }^{1,2, *}$ and Haruyuki Inui ${ }^{1,2}$

${ }^{1}$ Department of Materials Science and Engineering, Kyoto University

Sakyo-ku, Kyoto 606-8501, Japan

${ }^{2}$ Center for Elements Strategy Initiative for Structural Materials (ESISM),

Kyoto University, Sakyo-ku, Kyoto 606-8501, JAPAN

*Corresponding author: Kyosuke KISHIDA

Department of Materials Science and Engineering, Kyoto University, Sakyo-ku, Kyoto 606-8501, JAPAN

E-mail address: kishida.kyosuke.6w@kyoto-u.ac.jp

Tel.: +81-75-753-5461; fax: +81-75-753-5461

\begin{abstract}
Effects of ternary additions on the microstructure and thermal stability of directionallysolidified $\mathrm{MoSi}_{2} / \mathrm{Mo}_{5} \mathrm{Si}_{3}$ eutectic composites have been studied for twelve different elements (Ti, V, Cr, Fe, Co, Ni, Nb, Ta, W, Ir, B and C) paying special attention to the variation of lattice misfits and interface segregation behavior with ternary additions. Among six elements (type-1: Ti, V, Cr, Nb, Ta and W) with a relatively high solubility in $\mathrm{MoSi}_{2}$ and $\mathrm{Mo}_{5} \mathrm{Si}_{3}, \mathrm{Ta}$ and $\mathrm{W}$ are found to be beneficial to microstructure refinement. All other six ternary elements (type-2: Fe, Co, Ni, Ir, B and C) with a negligibly low solubility in $\mathrm{MoSi}_{2}$ and $\mathrm{Mo}_{5} \mathrm{Si}_{3}$ exhibit a strong tendency to segregate on $\mathrm{MoSi}_{2} / \mathrm{Mo}_{5} \mathrm{Si}_{3}$ interfaces, resulting in both microstructure refinement and the modification of the interface morphology.
\end{abstract}


Keywords: A. molybdenum silicides; B. alloy design, thermal stability, C. crystal growth; D. microstructure, phase interfaces;

\section{Introduction}

In recent years, there is a very strong demand for efficiency improvement of combustion systems for power plants and aircraft engines in order to reduce the consumption of fossil fuels and emission of greenhouse gases. One of the most effective ways to achieve this is to increase the operating temperature of gas turbine combustion systems, which currently achieve thermal efficiency about $40 \%$ as stand-alone units and over $60 \%$ when combining with steam turbine systems $[1,2]$. In the latest gas turbine systems with air-cooled turbine blades of Ni-based superalloys, the highest gas inlet temperature reaches to $1600{ }^{\circ} \mathrm{C}$, which is more than $200{ }^{\circ} \mathrm{C}$ higher than the melting temperature of the superalloy used [1]. As far as the combustion system relies on the air-cooling of turbine blades, any drastic increase in the operating temperature (and therefore in the thermal efficiency) may not be expected. From this perspective, it is evident that a new class of ultra-high-temperature structural materials that can be used in the severe oxidizing atmosphere at temperatures beyond the maximum operating temperatures of Ni-based superalloys has to be developed. Transition-metal silicides have been considered as promising candidates for replacing Ni-based superalloys mainly because of their high melting temperature mostly more than $2000{ }^{\circ} \mathrm{C}$ and expected good oxidation resistance at high temperatures [3-5]. Among various transition-metal silicides, a considerable amount of attention has been paid to $\mathrm{MoSi}_{2}$ with the tetragonal $\mathrm{C} 11_{\mathrm{b}}$ structure because of its high melting point $\left(2020{ }^{\circ} \mathrm{C}\right)$, excellent high-temperature oxidation resistance and relatively low density [3-9]. Mechanical properties of $\mathrm{MoSi}_{2}$, such as yield strength, fracture toughness and creep properties have been studied with the use of single crystals [7-11] and polycrystals [5,6]. Of particular interest is that in single crystals, plastic 
flow is possible by dislocation motion even at and below room temperature depending on crystal orientation $[7,9,10]$. Nevertheless, poor fracture toughness of monolithic $\mathrm{MoSi}_{2}$ around $3 \mathrm{MPa} \mathrm{m}{ }^{1 / 2}$ at room temperature has remained as one of the drawbacks, together with insufficient strength of polycrystals at high temperatures [3-5,9]. Extensive studies have been made to improve these drawbacks in mechanical properties by forming composites with hard ceramics such as $\mathrm{SiC}, \mathrm{TiC}, \mathrm{ZrO}_{2}, \mathrm{TiB}_{2}, \mathrm{Si}_{3} \mathrm{~N}_{4}$ through powder processing routes [3-5, 9, 1213]. Although modest improvement in fracture toughness is reported to achieve by these composites, some of them are reported to suffer from pesting, which is catastrophic oxidation that occurs in the temperature range of $400-600{ }^{\circ} \mathrm{C}$ especially when they are less dense [3-5, 15-18]. Since pesting is known to be suppressed to occur in single crystals of $\mathrm{MoSi}_{2}$ $[15,16,18], \mathrm{MoSi}_{2}$-based single crystalline composites produced by ingot metallurgy routes are considered to have great advantages over polycrystalline composites produced by powder metallurgy routes.

$\mathrm{MoSi}_{2} / \mathrm{Mo}_{5} \mathrm{Si}_{3}$ eutectic composites may be one of the promising candidates because of their high eutectic temperature $\left(1900{ }^{\circ} \mathrm{C}\right.$ for the binary alloy) and fine microstructures of the socalled script lamellar type formed simply by directional solidification (DS) $[9,13,18-26]$. Previous studies on $\mathrm{MoSi}_{2} / \mathrm{Mo}_{5} \mathrm{Si}_{3}$ eutectic composites have revealed that the creep properties are much superior to those of other $\mathrm{MoSi}_{2}$-based composites [21], while fracture toughness at room temperature for DS ingots of binary $\mathrm{MoSi}_{2} / \mathrm{Mo}_{5} \mathrm{Si}_{3}$ eutectic composites is still insufficient $[9,13]$. In the eutectic script lamellar structure in binary DS ingots, an orientation relationship of $(1 \overline{1} 0)_{\mathrm{MoSi}_{2}} / /(001)_{\mathrm{Mo5Si} 3}$ and $[110]_{\mathrm{MoSi}_{2}} / /[1 \overline{1} 0]_{\mathrm{Mo5Si}}$ is reported to occur between $\mathrm{MoSi}_{2}$ and $\mathrm{Mo}_{5} \mathrm{Si}_{3}$ with a growth direction being nearly parallel to $[1 \overline{1} 0]_{\mathrm{MoSi} 2}$ and $[001]_{\mathrm{Mo5}} \mathrm{Si} 3$ $[20,22]$. Two different types of main interphase boundaries have been noted; one with $(110)_{\mathrm{MoSi} 2} / /(1 \overline{1} 0)_{\mathrm{Mo5Si} 3}$ and another inclined by about $15^{\circ}$ from $(001)_{\mathrm{MoSi} 2} / /(110)_{\mathrm{Mo5Si} 3}$ (see Fig. 1). Since $\mathrm{MoSi}_{2}$ and $\mathrm{Mo}_{5} \mathrm{Si}_{3}$ both have body-centered tetragonal structures of $\mathrm{C}_{1} 1_{\mathrm{b}}$ and 
$\mathrm{D} 8_{\mathrm{m}}$-types, respectively, there is a high probability to control the interfacial energy through changing lattice misfits between the two phases by alloying, by which fracture toughness of the composites may be improved. In addition, segregation of a particular alloying element on the interphase boundary, if it occurs, may also influence fracture toughness of the composites through changing the cohesive energy of the boundary, as frequently reported in many metallic materials such as iron $[26,27]$. Since not only the microstructure but also the mechanical properties of $\mathrm{MoSi}_{2} / \mathrm{Mo}_{5} \mathrm{Si}_{3}$ eutectic composites are thus expected to vary with ternary alloying through the changes in the interfacial energy, it is quite important to establish microstructure-property relationships in $\mathrm{MoSi}_{2} / \mathrm{Mo}_{5} \mathrm{Si}_{3}$ eutectic composites upon ternary alloying. However, almost nothing is known about how the microstructure, its thermal stability and the resultant mechanical properties of $\mathrm{MoSi}_{2} / \mathrm{Mo}_{5} \mathrm{Si}_{3}$ eutectic composites are affected by ternary alloying, except for Er- and Nb-alloyed $\mathrm{MoSi}_{2} / \mathrm{Mo}_{5} \mathrm{Si}_{3}$ eutectic composites [20,23].

In the present paper, we report the effects of ternary additions of twelve different elements ( Ti, V, Cr, Fe, Co, Ni, Nb, Ta, W, Ir, B and C) on the microstructures and their thermal stability of DS ingots of $\mathrm{MoSi}_{2} / \mathrm{Mo}_{5} \mathrm{Si}_{3}$ eutectic composites, paying special attention to microstructural changes due to variations of lattice misfits and segregation of ternary elements. This is a part of our investigation of microstructure-property relationships in $\mathrm{MoSi}_{2} / \mathrm{Mo}_{5} \mathrm{Si}_{3}$ eutectic composites upon ternary alloying, and mechanical properties (yield strength, dislocation behavior and fracture toughness) of these ternary ingots will be published subsequently elsewhere.

\section{Experimental procedures}

Rod ingots of the binary alloy with a $\mathrm{MoSi}_{2} / \mathrm{Mo}_{5} \mathrm{Si}_{3}$ eutectic composition of Mo - 54 at.\% $\%$ i and ternary alloys with nominal compositions of Mo - 54 at. $\% \mathrm{Si}-x$ at.\%X $(\mathrm{X}=\mathrm{Ti}, \mathrm{V}$, 
Cr, Fe, Co, Ni, Nb, Ta, W and Ir, $x=0.1 \sim 5)$ and Mo $-(54-x)$ at.\%Si $-x$ at.\%X $(\mathrm{X}=\mathrm{B}$ and C, $x=0.15 \sim 2$ ) were prepared by arc-melting. DS ingots were grown from the rod ingots using an optical floating-zone furnace at various growth rates ranging from 2 to $200 \mathrm{~mm} / \mathrm{h}$ under an Ar gas flow. Average chemical compositions of all of the DS ingots were confirmed to be nearly identical to the nominal values with a minor deviation of less than about 1 at.\%. Parts of the DS ingots were heat-treated at $1500{ }^{\circ} \mathrm{C}$ for $500 \mathrm{~h}$ in vacuum. Microstructures of the DS and heat-treated ingots were examined by scanning electron microscopy (SEM) with a JEOL JSM-7001FA equipped with a field emission gun and by scanning transmission electron microscopy (STEM) with a JEOL JEM-2100F equipped with a field emission gun operated at $200 \mathrm{kV}$. Chemical compositions were analyzed by energy dispersive X-ray spectroscopy (EDS) in SEM and STEM. Lattice parameters for both phases in each alloy were determined by powder X-ray diffraction (XRD) method in order to estimate the lattice misfits at various $\mathrm{MoSi}_{2} / \mathrm{Mo}_{5} \mathrm{Si}_{3}$ interfaces.

\section{Results}

\subsection{Binary $\mathrm{MoSi}_{2} / \mathrm{Mo}_{5} \mathrm{Si}_{3}$ eutectic composites}

DS ingots of $\mathrm{MoSi}_{2} / \mathrm{Mo}_{5} \mathrm{Si}_{3}$ eutectic composites generally exhibit a so-called script lamellar structure [20]. Detailed orientation analysis by XRD, SEM-EBSD and TEM has confirmed that $\mathrm{MoSi}_{2}$ and $\mathrm{Mo}_{5} \mathrm{Si}_{3}$ phases in the script lamellar structure are grown nearly along $[1 \overline{1} 0]_{\mathrm{MoSi} 2}$ and $[001]_{\mathrm{Mo5Si} 3}$, maintaining the orientation relationship of $[110]_{\mathrm{MoSi} 2} / /$ $[1 \overline{1} 0]_{\mathrm{Mo5Si}}$ and $(1 \overline{1} 0)_{\mathrm{MoSi}_{2}} / /(001)_{\mathrm{Mo5Si}_{3}}$ with minor deviations of about $2^{\circ}$, as previously reported $[20,22]$.

SEM backscattered-electron images of three mutually orthogonal sections, cross $\left((1 \overline{1} 0)_{\mathrm{MoSi}_{2}} / /(001)_{\mathrm{Mo5Si} 3}\right)$ and two longitudinal $\left((110)_{\mathrm{MoSi} 2} / /(1 \overline{1} 0)_{\mathrm{Mo5Si}}\right.$ and $(001)_{\mathrm{MoSi} 2} / /$ $\left.(110)_{\mathrm{Mo5Si}}\right)$ sections of a DS ingot of a binary eutectic composite are shown in Figs. 1(a)-(c), 
respectively. Dark and bright regions in the figures correspond to $\mathrm{MoSi}_{2}$ and $\mathrm{Mo}_{5} \mathrm{Si}_{3}$ phases, respectively. Approximate crystallographic orientations for these sections are indicated in the figure. Fine microstructure composed of a $\mathrm{MoSi}_{2}$ matrix and an interconnected network of $\mathrm{Mo}_{5} \mathrm{Si}_{3}$ is developed with a macroscopic inclination of about $15^{\circ}$ from the growth direction, as clearly seen in the $(110)_{\mathrm{MoSi} 2} / /(1 \overline{1} 0)_{\mathrm{Mo5Si}}$ longitudinal section of the DS composite (Fig. $1(b))$.

From the microstructural characteristics, we have found that two types of interfaces, hereafter designated as interfaces I and II (Figs. 1 (j)-(1)), play important roles in determining the morphology and stability of microstructures. These two types of interfaces are perpendicular to each other in the $(1 \overline{1} 0)_{\mathrm{MoSi}_{2}} / /(001)_{\mathrm{Mo}_{5} \mathrm{Si} 3}$ cross section (Figs. 1 (a) and (j)). The interface I macroscopically inclined about $15^{\circ}$ from the growth direction in the $(110)_{\mathrm{MoSi} 2}$ // $(1 \overline{1} 0)_{\mathrm{Mo5Si} 3}$ longitudinal section (Figs. 1 (b) and (k)), has been reported to possess the socalled ledge-terrace structure at the atomic scale $[20,22]$. Approximate orientation relationships for the terrace and ledge parts of the interfaces I and II are described as follows.

$$
\begin{aligned}
& \text { Interface I, terrace part: }(001)_{\mathrm{MoSi}_{2}} / /(110)_{\mathrm{Mo5Si}_{3}} *,[110]_{\mathrm{MoSi} 2} / /[\overline{1} 10]_{\mathrm{Mo} 5 \mathrm{Si} 3} \text {, } \\
& \text { Interface I, ledge part: }(1 \overline{1} 0)_{\mathrm{MoSi} 2} / /(001)_{\mathrm{Mo5Si}_{3}} *,[110]_{\mathrm{MoSi} 2} / /[\overline{1} 10]_{\mathrm{Mo5Si} 3} \text {, } \\
& \text { Interface II: }(110)_{\mathrm{MoSi}_{2}} / /(\overline{1} 10)_{\mathrm{Mo5Si} 3},[001]_{\mathrm{MoSi}_{2}} / /[110]_{\mathrm{Mo5Si}_{3}} *
\end{aligned}
$$

The orientation relationships marked with asterisks are only approximate since slight misalignment is involved, details of which will be described later in this section.

With the orientation relationships described above, we have to consider three different types of lattice misfits, as proposed by Mason et al. [20]. These three types of lattice misfits are denoted as misfits $\mathrm{A}, \mathrm{B}$ and $\mathrm{C}$ as defined with the following equations:

$$
\text { Misfit } \mathrm{A}=2 \frac{d_{110 \text { of } \mathrm{MoSi}_{2}}-d_{330 \text { of } \mathrm{Mo}_{5} \mathrm{Si}_{3}}}{d_{110 \text { of } \mathrm{MoSi}_{2}}+d_{330 \text { of } \mathrm{Mo}_{5} \mathrm{Si}_{3}}}
$$




$$
\begin{aligned}
& \text { Misfit B }=2 \frac{d_{110 \text { of } \mathrm{MoSi}_{2}}-d_{002 \text { of } \mathrm{Mo}_{5} \mathrm{Si}_{3}}}{d_{110 \text { of } \mathrm{MoSi}_{2}}+d_{002 \text { of } \mathrm{Mo}_{5} \mathrm{Si}_{3}}} \\
& \text { Misfit C }=2 \frac{d_{002 \text { of } \mathrm{MoSi}_{2}}-d_{220 \text { of } \mathrm{Mo}_{5} \mathrm{Si}_{3}}}{d_{002 \text { of } \mathrm{MoSi}_{2}}+d_{220 \text { of } \mathrm{Mo}_{5} \mathrm{Si}_{3}}}
\end{aligned}
$$

where $d_{h k l \text { of } \mathrm{MoSi}_{2}}$ and $d_{h k l \text { of } \mathrm{Mo}_{5} \mathrm{Si}_{3}}$ indicate interplanar distances of $\{h k l\}$ planes in $\mathrm{MoSi}_{2}$ and $\mathrm{Mo}_{5} \mathrm{Si}_{3}$, respectively. Slight misalignment of about $2^{\circ}$ between $[1 \overline{1} 0]_{\mathrm{MoSi}_{2}}$ and $[001]_{\mathrm{Mo}_{5} \mathrm{Si}_{3}}$ is neglected here for simplicity. As seen in Fig. 2, the stability of the interface I should be affected by all three kinds of lattice misfits A, B and C, while that of the interface II is affected by misfits B and C.

Figs. 3(a) and (b) show typical examples of atomic-resolution high-angle annular darkfield (HAADF)-STEM images of the interfaces I and II observed in a thin foil cut parallel to the $(1 \overline{1} 0)_{\mathrm{MoSi}_{2}} / /(001)_{\mathrm{Mo5Si}}$ cross section in a DS ingot of a binary $\mathrm{MoSi}_{2} / \mathrm{Mo}_{5} \mathrm{Si}_{3}$ eutectic composite grown at a growth rate of $10 \mathrm{~mm} / \mathrm{h}$. These images were taken along $[001]_{\mathrm{Mo5} S \mathrm{Si}}$, which is nearly parallel to $[1 \overline{1} 0]_{\mathrm{MoSi}_{2}}$ and the growth direction of the DS ingot. In the atomicresolution HAADF-STEM images, atomic columns are imaged as bright spots, brightness of which is approximately proportional to the square of the average atomic number $(Z)$ in the atomic columns. Because of relatively large atomic number difference between Mo (42) and $\mathrm{Si}$ (14), only the atomic columns of Mo are imaged for the $\mathrm{Mo}_{5} \mathrm{Si}_{3}$ phase in Figs. 3(a) and (b) with the STEM equipment used in this study. In $\mathrm{MoSi}_{2}$ phase in Figs. 3(a) and (b) taken with the incident beam being parallel to $[001]_{\mathrm{Mo5} S i 3}$, atomic columns are not resolved and $(220)_{\mathrm{MoSi}_{2}}$ planes are imaged as bright horizontal lines, clearly indicating that there exists slight misalignment between $[1 \overline{1} 0]_{\mathrm{MoSi} 2}$ and $[001]_{\mathrm{Mo5Si} 3}$, while $(\overline{110})_{\mathrm{MoSi} 2}$ and $(1 \overline{1} 0)_{\mathrm{Mo5Si} 3}$ are perfectly parallel to each other. Both interfaces are atomistically flat except for some regions corresponding to ledges as indicated by black arrowheads. 
An atomic-resolution HAADF-STEM image and the corresponding selected-area electron diffraction (SAED) patterns taken from a region containing the interface $I$ in the edge-on configuration are shown in Figs. 3(c) and (d). These observations were made with a thin foil cut parallel to the $(110)_{\mathrm{MoSi}_{2}} / /(1 \overline{1} 0)_{\mathrm{Mo5Si} 3}$ longitudinal section in a DS ingot of a binary $\mathrm{MoSi}_{2} / \mathrm{Mo}_{5} \mathrm{Si}_{3}$ eutectic composite grown at a growth rate of $10 \mathrm{~mm} / \mathrm{h}$. Atomic columns of Mo that appear as bright spots are clearly resolved both in $\mathrm{MoSi}_{2}$ and in $\mathrm{Mo}_{5} \mathrm{Si}_{3}$ phases. This is consistent with the perfect alignment of $[110]_{\mathrm{MoSi}_{2}}$ and $[1 \overline{1} 0]_{\mathrm{Mo5Si} 3}$, both of which are parallel to the incident beam direction, although slight misalignment about $1.9^{\circ}$ between $[1 \overline{1} 0]_{\mathrm{MoSi} 2}$ and $[001]_{\mathrm{Mo5Si3}}$ is noted (Fig. 3(c) and (d)). The ledge-terrace structure described above is observed to be developed along the interface I shown in Fig. 3(c). These results are fully consistent with those previously reported [20, 22]. It is of importance to note that ledges with a height corresponding to the interplanar distance of $(110)_{\mathrm{Mo5} S i 3}$ are formed along the interface at an nearly regular interval, which is 13 times the interplanar distance of $(002)_{\mathrm{Mo5Si}}$ and 14 times that of $(110)_{\mathrm{MoSi}_{2}}$, resulting in a macroscopic inclination about $13.5^{\circ}$ of the interface from $[1 \overline{1} 0]_{\mathrm{MoSi} 2}$. This is consistent with the inclination angle about $15^{\circ}$ observed in the SEM images of the $(110)_{\mathrm{MoSi} 2} / /(1 \overline{1} 0)_{\mathrm{Mo5Si}}$ longitudinal section (Fig. 1(b)).

The eutectic microstructure of binary DS ingots varies depending on the growth rate, as shown in Figs. 1(d)-(i). The binary DS ingot obtained at a growth rate of $50 \mathrm{~mm} / \mathrm{h}$ (Figs. 1(d)-(f)) possesses a homogeneous and finer script lamellar structure when compared to that grown at a rate of $10 \mathrm{~mm} / \mathrm{h}$ (Figs. 1(a)-(c)). However, when the growth rate is increased to $200 \mathrm{~mm} / \mathrm{h}$, a cellular structure appears instead of the homogenous script lamellar structure. In the cellular structure, much finer script lamellar structure and very coarse lamellar structure are developed at the center of the cell and the cell boundary regions, respectively. Such growth-rate dependence of the eutectic microstructures has generally been observed in many 
eutectic alloys grown in a range of growth condition called 'coupled zone of eutectics' [28, 29].

\section{2 $\mathrm{MoSi}_{2} / \mathrm{Mo}_{5} \mathrm{Si}_{3}$ eutectic composites with ternary additions}

In the present study, the ternary elements added are found to be classified into two types according to their solubility in $\mathrm{MoSi}_{2}$ and $\mathrm{Mo}_{5} \mathrm{Si}_{3}$. Ternary elements, $\mathrm{Ti}, \mathrm{V}, \mathrm{Cr}, \mathrm{Nb}, \mathrm{Ta}$ and $\mathrm{W}$ that belong to groups $4-6$ in the periodic table exhibit a relatively high solubility in $\mathrm{MoSi}_{2}$ and $\mathrm{Mo}_{5} \mathrm{Si}_{3}$, while the others $(\mathrm{Fe}, \mathrm{Co}, \mathrm{Ni}, \mathrm{Ir}, \mathrm{B}$ and $\mathrm{C})$ possess a quite low solubility below 1 at. $\%[30,31]$. The former and latter are hereafter designated as type- 1 and type- 2 elements, respectively, and their microstructural variations will be described in the separate sections.

\subsubsection{Ternary $\mathrm{MoSi}_{2} / \mathrm{Mo}_{5} \mathrm{Si}_{3}$ eutectic composites with the type-1 elements (Ti, $\mathrm{V}, \mathrm{Cr}, \mathrm{Nb}, \mathrm{Ta}$ and $W$ )}

\subsubsection{Microstructure}

As expected from relatively large solubilities of these ternary elements of the type- 1 in $\mathrm{MoSi}_{2}$ and $\mathrm{Mo}_{5} \mathrm{Si}_{3}$ in literature [30, 31], two-phase $\mathrm{MoSi}_{2} / \mathrm{Mo}_{5} \mathrm{Si}_{3}$ eutectic microstructures are usually obtained without any ternary phase for all composites up to the 5 at.\% addition, which corresponds to the maximum amount of ternary additions used in this study. However, microstructural characteristics vary depending on the ternary elements. SEM backscatteredelectron images of the $(1 \overline{1} 0)_{\mathrm{MoSi}_{2}} / /(001)_{\mathrm{Mo5} 53}$ cross section of ternary $\mathrm{MoSi}_{2} / \mathrm{Mo}_{5} \mathrm{Si}_{3}$ DS ingots alloyed with 5 at.\% Nb, Ta and $\mathrm{W}$ are shown in Figs. 4(a)-(c), respectively. All ingots were obtained at a growth rate of $10 \mathrm{~mm} / \mathrm{h}$. DS ingots alloyed with $\mathrm{Nb}$ and Ta possess a homogeneous script lamellar structure when the amount of additions is small (less than 5 at.\%), whereas when the amount of additions reaches 5 at.\%, ingots tend to contain a small amount of an additional primary solidification phase ( $\mathrm{MoSi}_{2}$ (Fig. 4(a)) and $\mathrm{Mo}_{5} \mathrm{Si}_{3}$ (Fig. 4(b)) for $\mathrm{Nb}$ - and Ta-alloyed ingots, respectively). This may indicate the deviation of the eutectic composition from the Mo - 54 at.\% $\mathrm{Si}$ composition upon alloying with a large amount 
of these elements, $\mathrm{Nb}$ and $\mathrm{Ta}$. In contrast, $\mathrm{DS}$ ingots with $\mathrm{W}$ additions maintain a homogeneous script lamellar structure up to the 5 at.\% addition. Microstructural characteristics in the homogeneous script lamellar structure in ternary DS ingots alloyed with $\mathrm{Nb}$, Ta and $\mathrm{W}$ are virtually identical to those observed in the binary ingot grown at the same growth rate of $10 \mathrm{~mm} / \mathrm{h}$ (Fig. 1(a)), except that Ta- and $\mathrm{W}$-alloyed DS ingots possess a slightly finer microstructure than the binary DS ingot does.

In contrast, Ti-, V- and Cr-alloyed DS ingots exhibit a strong tendency to form a cellular eutectic structure with dispersed irregularity in microstructure when DS ingots are grown at a growth rate of $10 \mathrm{~mm} / \mathrm{h}$. Typical microstructures observed in the $(1 \overline{1} 0)_{\mathrm{MoSi}_{2}} / /(001)_{\mathrm{Mo5Si}_{3}}$ cross section of DS ingots alloyed with various amounts of $\mathrm{Ti}, \mathrm{V}$ and $\mathrm{Cr}$ grown at a growth rate of $10 \mathrm{~mm} / \mathrm{h}$ are shown in Figs. 5(a)-(f). The cellular eutectic structure developed in DS ingots with 5 at.\% additions of Ti (Fig. 5(b)) and V (Fig. 5(d)) and that with 1 at.\% Cr (Fig. 5(e)) consists of a fine script lamellar structure at a central part of each columnar cell and a very coarse and irregularly-shaped lamellar structure in cell boundary regions, while DS ingots with lessor amounts of $\mathrm{Ti}$ and $\mathrm{V}$ additions exhibit a relatively homogeneous script lamellar structure (Figs. 5(a) and (c)). Neither script lamellar structure nor cellular structure is observed any more in a 5 at.\% Cr-alloyed DS ingot obtained at a growth rate of $10 \mathrm{~mm} / \mathrm{h}$ (Fig. 5(f)) and a coarse and irregular eutectic structure is observed instead. Such variations in the eutectic structures are generally interpreted in terms of the degree of undercooling during solidification. It is well-known that the eutectic structure formed under a growth condition called 'coupled zone of eutectics' changes from planar eutectic structure to cellular eutectic, and to faceted eutectic dendrites with the increase in the growth rate (i.e., the degree of undercooling) $[28,29]$. In the present eutectic composites, the planar eutectic structure corresponds to the homogeneous script lamellar structure. Since the growth rate is the same for all DS ingots shown in Figs. 5(a)-(f), the observed changes in the eutectic microstructure 
of Ti-, V-and Cr-alloyed DS ingots are considered to be caused by the relative increase in the degree of undercooling. In fact, the homogeneous script lamellar structure was obtained by reducing the amount of ternary addition and by decreasing the growth rate for Cr-alloyed DS ingots. For DS ingots alloyed with 1 at.\% Cr, the cellular eutectic structure and homogeneous script lamellar structure are obtained when the growth rate is high $(10 \mathrm{~mm} / \mathrm{h})$ and low $(2$ $\mathrm{mm} / \mathrm{h})$, as shown respectively in Figs. 5(e) and (g).

Although the microstructure of $\mathrm{MoSi}_{2} / \mathrm{Mo}_{5} \mathrm{Si}_{3}$ eutectic composites varies with the growth rate, the microstructural variation of the homogeneous script lamellar structure with ternary additions is less pronounced when the microstructure in the $(1 \overline{1} 0)_{\mathrm{MoSi}_{2}} / /(001)_{\mathrm{Mo5Si}}$ cross section of DS ingots is inspected (Figs. 4 and 5). This is also the case for the homogeneous script lamellar structure inspected in the $(110)_{\mathrm{MoSi}_{2}} / /(1 \overline{1} 0)_{\mathrm{Mo5Si} 3}$ longitudinal section (Fig. 6). Flat portions that incline about $15^{\circ}$ from the growth direction are maintained for the interface I in ternary DS ingots alloyed with 5 at.\% V (Fig. 6(a)), 5 at.\% Ta (Fig. 6(b)) and 2 at.\% W (Fig. 6 (c)), although the extent of perturbation of the interface flatness varies somehow with ternary elements.

\subsubsection{Partitioning behavior and lattice misfits}

Chemical compositions of $\mathrm{MoSi}_{2}, \mathrm{Mo}_{5} \mathrm{Si}_{3}$ and some ternary phases evaluated in binary and ternary DS ingots by SEM-EDS are summarized in Table 1 for type-1 alloying elements. For all type- 1 elements except for $\mathrm{W}$, they are partitioned preferentially in the $\mathrm{Mo}_{5} \mathrm{Si}_{3}$ phase, while $\mathrm{W}$ is partitioned more or less evenly in $\mathrm{MoSi}_{2}$ and $\mathrm{Mo}_{5} \mathrm{Si}_{3}$ phases.

Lattice parameters of the constituent phases in binary and some ternary DS ingots alloyed with type- 1 elements estimated by the powder XRD method are also summarized in Table 1. Lattice constants of the $\mathrm{MoSi}_{2}$ phase in DS ingots alloyed with these type- 1 alloying elements are all identical with each other, reflecting the negligibly small solubility in $\mathrm{MoSi}_{2}$ for $\mathrm{Ti}, \mathrm{V}$, $\mathrm{Cr}, \mathrm{Nb}$ and $\mathrm{Ta}$ and the similarity in atomic radii for Mo $(0.140 \mathrm{~nm})$ and $\mathrm{W}(0.141 \mathrm{~nm})$ [32]. 
In contrast, the $\mathrm{Mo}_{5} \mathrm{Si}_{3}$ phase exhibit relatively large variations in lattice parameters with ternary additions, trends of which can be interpreted primarily in terms of the difference in atomic radii between $\mathrm{Mo}$ and the corresponding ternary element. For $\mathrm{Nb}(0.147 \mathrm{~nm})$ and $\mathrm{Ta}$ $(0.147 \mathrm{~nm})$ with an atomic radius larger than Mo, both $a$ - and $c$-axis lattice parameters increase with the increase in the amount of ternary addition, while the opposite is the case for $\mathrm{V}(0.135 \mathrm{~nm})$ and $\mathrm{Cr}(0.128 \mathrm{~nm})$ with an atomic radius smaller than Mo. Additions of $\mathrm{Ti}$ $(0.146 \mathrm{~nm})$ result in an anisotropic expansion preferentially along the $a$-axis without any significant change along the $c$-axis. These results are well consistent with the previous report [33].

Values of lattice misfit for misfits A, B and C given in equations (1a)-(1c) are summarized in Fig. 7 as a function of the amount of alloying for type-1 alloying elements, based on the results summarized in Table 1. The absolute values of the lattice misfits A and B increase and that of the lattice misfit $\mathrm{C}$ decreases with the increase in the amount of $\mathrm{Nb}$ and $\mathrm{Ta}$ additions. The completely opposite trend is observed for $\mathrm{V}$ and $\mathrm{Cr}$ additions, i.e., the absolute values of the lattice misfits $\mathrm{A}$ and $\mathrm{B}$ decrease and that of the lattice misfit $\mathrm{C}$ increases with the increase of their additions. On the other hand, Ti additions result in basically the same trend for the lattice misfits $\mathrm{A}$ and $\mathrm{C}$ as $\mathrm{Nb}$ and $\mathrm{Ta}$ additions, whereas the lattice misfit $\mathrm{B}$ is nearly unchanged because almost no change occurs in the $c$-axis lattice constant. Although changes in lattice misfit values upon alloying vary with ternary elements, the absolute values of lattice misfits of the three different types do not change significantly. The values of lattice misfits B and $\mathrm{C}$ remain high (about 8 and $14 \%$ ) with the change occurring in the range of 1 and $0.5 \%$ upon alloying, whereas that of misfit A remain small (less than \%) with the change in the range of $0.5 \%$. This may be one of the reasons why the flat portions with an inclination about $15^{\circ}$ from the growth direction are maintained for the interface I irrespective of ternary elements, details of which are described later in the discussion section. 


\subsubsection{Ternary $\mathrm{MoSi}_{2} / \mathrm{Mo}_{5} \mathrm{Si}_{3}$ eutectic composites with the type-2 elements (Fe, Co, $\mathrm{Ni}, \mathrm{Ir}, \mathrm{B}$,}

C)

\subsubsection{Microstructure}

SEM backscattered-electron images of the $(1 \overline{1} 0)_{\mathrm{MoSi}_{2}} / /(001)_{\mathrm{Mo5Si}}$ cross section of ternary $\mathrm{MoSi}_{2} / \mathrm{Mo}_{5} \mathrm{Si}_{3} \mathrm{DS}$ ingots alloyed with 2 at.\% Fe, Co, Ni, 0.2 at.\% Ir, 2 at.\% B and 1 at.\% C (type-2 elements) grown at a growth rate of $10 \mathrm{~mm} / \mathrm{h}$ are shown in Fig. 8. As seen in Table 2 which summarizes chemical compositions of $\mathrm{MoSi}_{2}, \mathrm{Mo}_{5} \mathrm{Si}_{3}$ and some ternary phases in the ternary DS ingots containing type-2 alloying elements, the solid solubilities of these type-2 alloying elements in both the $\mathrm{MoSi}_{2}$ and $\mathrm{Mo}_{5} \mathrm{Si}_{3}$ phases are all negligibly small. A very coarse and irregularly-shaped eutectic structure is observed in Fe-, Co-, Ni- and Ir-alloyed DS ingots accompanied by the formation of an additional ternary phase on some of the $\mathrm{MoSi}_{2} / \mathrm{Mo}_{5} \mathrm{Si}_{3}$ interfaces (Figs. 8(a)-(d)). Ternary phases in DS ingots alloyed with Fe, Co, Ni and $\mathrm{Ir}$ are inferred respectively to be $\mathrm{MoFe}_{2} \mathrm{Si}_{2}$ or $\mathrm{MoFe}_{2}, \mathrm{MoCoSi}, \mathrm{MoNiSi}$ and IrSi based on the chemical composition revealed by EDS and previously reported phase diagrams [31]. The B-alloyed DS ingots exhibits a cellular structure similar to those observed in DS ingots with additions of 5 at.\% $\mathrm{V}$ and Ti (Fig. 6). An additional ternary phase is also noted to form on some of the $\mathrm{MoSi}_{2} / \mathrm{Mo}_{5} \mathrm{Si}_{3}$ interfaces as clearly seen at a higher magnification (Fig. 8(f)). The ternary phase in the DS ingot alloyed with $\mathrm{B}$ is similarly inferred to be MoB [31]. On the other hand, the C- alloyed DS ingot exhibits a homogeneous script lamellar structure, although an additional ternary phase, which is inferred to be $\mathrm{Mo}_{5} \mathrm{Si}_{3} \mathrm{C}$ [31], is also noted to form on some of the $\mathrm{MoSi}_{2} / \mathrm{Mo}_{5} \mathrm{Si}_{3}$ interfaces as clearly seen at a higher magnification (Fig. $8(\mathrm{~g})$ and $(\mathrm{h}))$.

These ternary phases usually observed in DS ingots alloyed with type-2 alloying elements can be eliminated by decreasing the amounts of these additions to less than 0.2 at.\%. Typical examples of the homogeneous script lamellar structure observed in the $(1 \overline{1} 0)_{\mathrm{MoSi}_{2}} / /(001)_{\mathrm{Mo5Si} 3}$ 
cross section and $(110)_{\mathrm{MoSi}_{2}} / /(1 \overline{1} 0)_{\mathrm{Mo5Si}_{3}}$ and $(001)_{\mathrm{MoSi}_{2}} / /(110)_{\mathrm{Mo5}} \mathrm{Si}_{3}$ longitudinal sections of DS ingots alloyed with 0.1 at.\% Co, 0.16 at.\% B (=300 wt.ppm B) and 0.15 at.\% C (=300 wt.ppm C) are shown in Fig. 9. It is easily recognized that the ternary phases are completely eliminated from the ingots and that the homogeneous script lamellar structures observed in the $(1 \overline{1} 0)_{\mathrm{MoSi}_{2}} / /(001)_{\mathrm{Mo5Si}_{3}}$ cross section of the ternary ingots are finer than that observed in binary DS ingots (Figs. 1(a)-(c)) obtained at the same growth rate of $10 \mathrm{~mm} / \mathrm{h}$. On top of that, these ternary DS ingots alloyed with 0.1 at.\% Co, 0.16 at.\% B and 0.15 at.\% C lose almost all flat portions of the interface I (evident when viewed in the $(110)_{\mathrm{MoSi}_{2}} / /(1 \overline{1} 0)_{\mathrm{Mo5Si}_{3}}$ longitudinal section; Figs. 9(b), (e) and (h)).

\subsubsection{Interface segregation of the ternary elements of type 2}

Because of the negligibly small solubility of type-2 elements in the $\mathrm{MoSi}_{2}$ and $\mathrm{Mo}_{5} \mathrm{Si}_{3}$ phases, segregation of these alloying elements on the $\mathrm{MoSi}_{2} / \mathrm{Mo}_{5} \mathrm{Si}_{3}$ interface is expected. Chemical compositions across the $\mathrm{MoSi}_{2} / \mathrm{Mo}_{5} \mathrm{Si}_{3}$ interface were analyzed by STEM-EDS using thin foils cut parallel to the $(1 \overline{10})_{\mathrm{MoSi}_{2}} / /(001)_{\mathrm{Mo5} S 3}$ cross section, in order to investigate the segregation behavior of some of type-2 elements. Figs. 10(a) and (b) show the results of EDS analysis made respectively for the interfaces I and II in a DS ingot alloyed with 0.5 at.\% Co grown at a rate of $10 \mathrm{~mm} / \mathrm{h}$. Significant segregation of Co is clearly seen to occur on both types of interfaces, so that the chemical composition of Co on the interface is as high as 3 to 5 times that of the $\mathrm{Mo}_{5} \mathrm{Si}_{3}$ matrix. Segregation of Ni and Ir is similarly observed to occur on both types of interfaces, as shown in Figs. 10(c) and (d). Variations of chemical compositions across the interface I in a DS ingots alloyed with 0.5 at.\% Ni were inspected by STEM-EDS, as shown in Fig. 11. Although the flat portions (inclined by $15^{\circ}$ from the growth direction in the binary counterpart) of the interface I are almost completely lost upon alloying with type-2 elements (Fig. 9), portions corresponding to the ledge and terrace parts are observed still to exist without having any regularity for their arrangement, as clearly seen in an atomic-scale 
image shown in Fig. 11(a). The extent of segregation of Ni exactly on the boundary is much higher in the ledge portion than in the terrace portion (Fig. 11(c)). Similar anisotropic segregation behaviors were observed also for DS ingots alloyed with Co and Ir. We expect a similar anisotropic segregation behaviors for other type-2 alloying elements, when judged from the similar tendency in the solid solubility in the $\mathrm{MoSi}_{2}$ and $\mathrm{Mo}_{5} \mathrm{Si}_{3}$ phases and the microstructure variation upon alloying.

\subsection{Thermal stability of microstructure}

In order to confirm the thermal stability of the eutectic microstructure, annealing experiments were made for various DS ingots at $1500{ }^{\circ} \mathrm{C}$ for $500 \mathrm{~h}$ in vacuum. No apparent changes in microstructure were detected for all DS ingots examined, indicating the very high thermal stability of the $\mathrm{MoSi}_{2} / \mathrm{Mo}_{5} \mathrm{Si}_{3}$ eutectic microstructure even at a very high temperature of $1500^{\circ} \mathrm{C}$.

\section{Discussion}

\subsection{Relationship between lattice misfits and interface structure}

In the script lamellar structure of binary two-phase $\mathrm{MoSi}_{2} / \mathrm{Mo}_{5} \mathrm{Si}_{3}$ eutectic composites, a characteristic ledge-terrace structure is observed to form at the interface I. The ledge-terrace structure of the interface I is revealed through atomic-resolution HAADF-STEM imaging to consist of regularly-spaced ledges with a fixed height corresponding to the interplanar distance of $(110)_{\mathrm{Mo5}} \mathrm{Si}$. Since a ledge-terrace structure is generally considered to form to accommodate lattice misfits between two phases in a particular orientation relationship [34, 35], it should be important to consider the relationship between the observed interface microstructure and the misfit accommodation. For simplicity, we consider here two types of lattice misfits $\mathrm{B}$ and $\mathrm{C}$, which correspond primarily to those at the terrace and ledge parts of the interface I, respectively. Since the absolute value of the misfit C ( $\sim 13 \%$ for the binary 
alloy) is larger than that of the misfit $\mathrm{B}(\sim 8 \%)$, the accommodation for the misfit $\mathrm{C}$ is considered first. Figure 12 schematically illustrates misfit accommodation achieved by tilting one of the two crystals with respect to the other across the interface. As shown in Fig. 12(b), if a small tilt (with the angle $\phi$ ) is introduced for one of the two crystals ( $\mathrm{Mo}_{5} \mathrm{Si}_{3}$ in this case), the lattice misfit $\mathrm{C}$ is eliminated on the interface labeled $\mathrm{OP}$, which is inclined both from $(001)_{\mathrm{MoSi}_{2}}$ and from $(110)_{\mathrm{Mo5Si} 3}$. Such a macroscopic inclination of the interface I through the introduction of a ledge-terrace structure (Fig. 12(c)) is indeed observed to occur in the script lamellar structure of binary two-phase $\mathrm{MoSi}_{2} / \mathrm{Mo}_{5} \mathrm{Si}_{3}$ eutectic composites (Figs. 1(b), (e) and (h)). The angle $\theta$ for the macroscopic inclination of the interface I from $(001)_{\mathrm{MoSi}_{2}}$ is correlated with the tilt angle $\phi$ with the following equation.

$$
\tan \theta=\frac{d_{001 \text { of } \mathrm{MoSi}_{2}} \cdot \sin \phi}{d_{001 \text { of } \mathrm{MoSi}_{2}} \cdot \cos \phi-d_{110 \text { of } \mathrm{Mo}_{5} \mathrm{Si}_{3}}}
$$

In the case of the interface I formed during solidification, the interface inclination angle must be determined so as to minimize the misfit strain related not only to the misfit $\mathrm{C}$ but also to the misfit $\mathrm{B}$. The misfit strain related to the misfit $\mathrm{B}$ is expected to be minimized when the following relation is satisfied, in addition to the equation (2).

$$
\left(m \cdot d_{110 \text { of } \mathrm{MoSi}_{2}}\right)^{2}+\left(d_{001 \text { of } \mathrm{MoSi}_{2}}\right)^{2}=\left(n \cdot d_{002 \text { of } \mathrm{Mos}_{5} \mathrm{Si}_{3}}\right)^{2}+\left(d_{110 \text { of } \mathrm{Mos}_{5} \mathrm{Si}_{3}}\right)^{2}
$$

where $m$ and $n$ are integers. If $m$ is equal to $n$, no misfit strain remains macroscopically at the interface. If $m$ is not equal to $n$, a semi-coherent interface containing a single set of interface dislocations with a regular interval is formed. However, that the equation (3) is not exactly satisfied with integer values for $m$ and $n$, because of the lattice parameters for $\mathrm{MoSi}_{2}$ and $\mathrm{Mo}_{5} \mathrm{Si}_{3}$. Approximate solutions can be found by plotting the left and right sides of the equation (3) as a function of the tilt angle $\phi$. This is done in Fig. 13(a) with the use of the lattice parameters for binary $\mathrm{MoSi}_{2}\left(a_{\mathrm{MoSi} 2}=0.321 \mathrm{~nm}, c_{\mathrm{MoSi} 2}=0.785 \mathrm{~nm}\right)$ and $\mathrm{Mo}_{5} \mathrm{Si}_{3}$ 
$\left(a_{\mathrm{Mo5Si} 3}=0.966 \mathrm{~nm}, c_{\mathrm{Mo5Si} 3}=0.490 \mathrm{~nm}\right)$ at room temperature (Table 1). The expected tilt angle $\phi$ can be estimated from the following equations.

$$
\begin{aligned}
& m \cdot d_{110 \text { of } \mathrm{MoSi}_{2}}=\frac{d_{001 \text { of } \mathrm{MoSi}_{2}} \cdot \cos \phi-d_{110 \text { of } \mathrm{MoS}_{5} \mathrm{Si}_{3}}}{\sin \phi} \\
& n \cdot d_{002 \text { of } \mathrm{Mo}_{5} \mathrm{Si}_{3}}=\frac{d_{001 \text { of } \mathrm{MoSi}_{2}}-d_{110 \text { of } \mathrm{Mo}_{5} \mathrm{Si}_{3}} \cdot \cos \phi}{\sin \phi}
\end{aligned}
$$

Inspection of the figure reveals that the values of the left and right sides of equation (3) almost coincide with each other at a tilt angle about $1.71^{\circ}$, at which $m$ and $n$ are 15 and 14 , respectively. The macroscopic inclination angle $\theta$ of the interface I from $(001)_{\mathrm{MoSi}_{2}}$ is then calculated to be about $13.0^{\circ}$. These values are quite close to those experimentally observed in Figs. 1(b), 3(c) and 3(d), where $m, n, \phi$ and $\theta$ are $14,13,1.9^{\circ}$ and $13.5^{\circ}$, respectively. Slight differences for values of $m$ and $n$ are considered to reflect the difference in the lattice parameters between room temperature and the eutectic temperature of $1900^{\circ} \mathrm{C}$. If we assume that coefficients for linear thermal expansion for $\mathrm{MoSi}_{2}$ and $\mathrm{Mo}_{5} \mathrm{Si}_{3}[36,37]$ are constant up to the eutectic temperature, the lattice parameters for binary $\mathrm{MoSi}_{2}$ and $\mathrm{Mo}_{5} \mathrm{Si}_{3}$ at the eutectic temperature can be estimated to be $a_{\mathrm{MoSi} 2}=0.326 \mathrm{~nm}, c_{\mathrm{MoSi} 2}=0.799 \mathrm{~nm}$ and $a_{\mathrm{Mo5Si} 3}=0.975$ $\mathrm{nm}, c_{\mathrm{Mo5Si} 3}=0.501 \mathrm{~nm}$, respectively. With the use of these lattice parameters, the values $m, n$, $\phi$ and $\theta$ are calculated to be $14,13,1.93^{\circ}$ and $13.9^{\circ}$, respectively, which are almost perfectly consistent with those experimentally observed. We can thus conclude that the $\mathrm{MoSi}_{2} / \mathrm{Mo}_{5} \mathrm{Si}_{3}$ eutectic microstructure grows so as to minimize the misfit strain at the interface I during solidification.

We now evaluate how the lattice misfits affect the interface structure and morphology of the interface I in DS ingots alloyed with type-1 elements by estimating the values $m, n, \phi$ and $\theta$ with the lattice parameters determined for ternary elements of type-1 (Table 1). The evaluation was made for DS ingots with additions of 5 at. $\% \mathrm{~V}$ and 5 at.\% Ta, since relatively 
large changes in lattice misfits are observed upon alloying with these elements (Fig. 4). The results of the evaluation for the V-alloyed and Ta-alloyed DS ingots are shown in Figs. 13(b) and (c), respectively. The values of $m, n, \phi$ and $\theta$ for the 5 at. $\%-\mathrm{V}$ alloyed DS ingot are estimated respectively to be $16,15,1.64^{\circ}$ and $12.2^{\circ}$, while those for the 5 at.\%-Ta alloyed one are $14,13,1.77$ and $13.9^{\circ}$. These values are not so much different from those calculated for the binary counterpart. This is consistent with the fact that no significant change in the morphology of the flat portions of the interface I is noted upon alloying with type- 1 alloying elements (Fig. 7).

Although the lattice misfits induced by ternary alloying do not alter significantly the morphology of the interface I in DS ingots alloyed with type-1 elements, the interface energy is expected to change upon alloying through the changes in the values $m$ and $n$. This is because the difference in number between $m$ and $n$ corresponds to the number of interfacial dislocations (with the extra-half plane on the $\mathrm{MoSi}_{2}$ side when $m>n$ ) in a terrace part of the interface I (Fig. 12(c)), since $m$ and $n$ are the numbers of $(110)_{\mathrm{MoSi}_{2}}$ and (002) $)_{\mathrm{Mo5Si}}$ atomic planes in the terrace part. If the number difference between $m$ and $n$ is one, each terrace contains single interfacial dislocation, and the interval of interfacial dislocations in that case is identical with the length of each terrace, which corresponds to the value of $m$ (or $n$ ). The interfacial energy is expected to increase with the increase in the interfacial dislocation density (i.e., with the decrease in the interval of interfacial dislocations). For all three different alloys shown in Fig. 13, the number difference between $m$ and $n$ is one. The interfacial dislocation density in the interface I is thus basically determined by the value of $m$ (or $n$ ). We thus expect the highest interfacial energy for the 5 at.\% Ta-alloyed DS ingot (Fig. $13(\mathrm{c}) ; m=14)$ of the three alloys while the lowest energy for the 5 at.\% V-alloyed DS ingot (Fig. 13(c); $m=16$ ). Our preliminary results indeed indicate that the Ta-alloyed DS ingots exhibit the highest propensity for delamination along the interface I on fracture toughness 
evaluation with an indentation fracture method. This result suggests the possibility that the fracture toughness of $\mathrm{MoSi}_{2} / \mathrm{Mo}_{5} \mathrm{Si}_{3}$ eutectic composites can be improved by increasing the interfacial energy through lattice misfit control by alloying type-1 elements such as Ta and W. Fracture toughness improvement of $\mathrm{MoSi}_{2} / \mathrm{Mo}_{5} \mathrm{Si}_{3}$ eutectic composites through interfacial energy control is currently under survey in our group.

\subsection{Relationship between segregations of ternary elements and microstructures}

Alloying elements of the type 2 (such as $\mathrm{Co}$, Ni and Ir) that have a negligibly low solubility in both $\mathrm{MoSi}_{2}$ and $\mathrm{Mo}_{5} \mathrm{Si}_{3}$ phases exhibit a strong tendency to segregate on the $\mathrm{MoSi}_{2} / \mathrm{Mo}_{5} \mathrm{Si}_{3}$ interface in the homogeneous script lamellar structure of $\mathrm{MoSi}_{2}$ and $\mathrm{Mo}_{5} \mathrm{Si}_{3}$ eutectic composites. In general, the stability of interphase boundaries is discussed in terms of the interfacial energy, which can be divided into the elastic term due to the lattice misfits and the chemical term due to atomic bonding across the interface. Since the solid-solubility of type-2 elements in both $\mathrm{MoSi}_{2}$ and $\mathrm{Mo}_{5} \mathrm{Si}_{3}$ phases is negligibly small, changes in the elastic term of the interfacial energy is expected to be very small in ternary $\mathrm{MoSi}_{2} / \mathrm{Mo}_{5} \mathrm{Si}_{3}$ eutectic composites alloyed with type-2 elements, when compared with the binary counterpart. Thus, the change in the chemical interaction energy across the interface is considered to play a dominant role in modifying the morphology (i.e., in losing the flat portions) (Figs. 8(b), 8(e) and $8(\mathrm{~h}))$ of the interface I in $\mathrm{MoSi}_{2} / \mathrm{Mo}_{5} \mathrm{Si}_{3}$ eutectic composites alloyed with type- 2 elements. In fact, segregation of $\mathrm{Ni}$ (and $\mathrm{Co}$, and Ir) on the $\mathrm{MoSi}_{2} / \mathrm{Mo}_{5} \mathrm{Si}_{3}$ interphase boundary is observed to occur with the extent of segregation being more significant in the ledge part than in terrace part of the interface I (Fig. 11). Segregation of these elements is considered to result in lowering the interfacial energy, which occurs more effectively in the ledge part than in terrace part of the interface I, causing a decrease in the relative energy difference between ledge and terrace parts. We believe that such a decrease in the relative energy difference between ledge and terrace parts is responsible for the observed loss of the flat portions of the 
interface I. The interfacial energy caused by the segregation of the type- 2 elements is also considered play an important role for the interlamellar spacing in the script-lamellar structure. According to the simple thermodynamic estimation by Zener [38], minimum interlamellar spacing is proportional to the interfacial energy and inversely proportional to the degree of undercooling. Since the slight ternary addition of the type- 2 elements is not likely to alter the degree of undercooling much in the cases of the DS alloys with the type- 2 elements, the observed finer lamellar spacing is considered to be mainly affected by the lower interfacial energy caused by the segregation of the type- 2 elements. The ternary addition of the type- 2 elements is thus effective for fabricating finer microstructure, which is expected to be beneficial in improving mechanical properties of the DS eutectic ingots, especially for high temperature strength.

\section{Conclusions}

1. The microstructure of directionally-solidified $\mathrm{MoSi}_{2} / \mathrm{Mo}_{5} \mathrm{Si}_{3}$ eutectic composites varies depending on the degree of undercooling, which can be controlled by changing the growth rate, and the ternary addition. The eutectic structure changes from planar eutectic (homogeneous script lamellar) to cellular eutectic, and to faceted eutectic dendrites with the increase in the growth rate or the degree of undercooling.

2. Among six type-1 elements $(\mathrm{Ti}, \mathrm{V}, \mathrm{Cr}, \mathrm{Nb}, \mathrm{Ta}$ and $\mathrm{W})$ with a relatively high solubility in $\mathrm{MoSi}_{2}$ and $\mathrm{Mo}_{5} \mathrm{Si}_{3}$, microstructure refinement is achieved by additions of $\mathrm{Ta}$ and $\mathrm{W}$. Although the morphology of flat portions of the interface I (with an inclination about $15^{\circ}$ from the growth direction) in the homogeneous script lamellar structure is not significantly altered upon alloying these elements, the interface energy is considered to change upon alloying through the changes in lattice misfits, i.e., the numbers of (110) $)_{\mathrm{MoSi}_{2}}$ and (002) $)_{\mathrm{Mo5Si} 3}$ atomic planes in the terrace part of the ledge-terrace structure of the interface I. 
3. A strong segregation on the interphase boundary is noted for type-2 alloying elements (Fe, $\mathrm{Co}, \mathrm{Ni}, \mathrm{Ir}, \mathrm{B}, \mathrm{C})$ whose solubility in $\mathrm{MoSi}_{2}$ and $\mathrm{Mo}_{5} \mathrm{Si}_{3}$ is negligibly small. As a result, microstructure refinement occurs upon alloying with these elements at a very small level of alloying additions (less than about $0.1 \sim 0.16$ at.\%). The observed loss of the flat portions of the interface I in the homogeneous script lamellar structure is considered to occur due to the fact that the interface energy is reduced by segregation of type- 2 alloying elements.

4. The eutectic structure developed during directional solidification is stable after heat treatment at $1500^{\circ} \mathrm{C}$ and for 500 hours, irrespective ternary elements.

\section{Acknowledgements}

This work was supported by the Advanced Low Carbon Technology Research and Development Program (ALCA) from the Japan Science and Technology Agency (JST) and in part by the Elements Strategy Initiative for Structural Materials (ESISM) from the Ministry of Education, Culture, Sports, Science and Technology (MEXT), Japan, and in part by JSPS KAKENHI (Nos. 24246113 and 25630304).

\section{References}

1. S. Hada, K. Tsukagoshi, J. Masada, E. Ito, Test results of the world's first $1,600^{\circ} \mathrm{C}$ Jseries gas turbine, Mitsubishi Heavy Ind. Tech. Rev., 49 (2012) 18-23.

2. G.G. Ol'khovskii, Prospective gas turbine and combined cycle units for power engineering (a review), Therm. Eng., 60 (2013) 79-88.

3. A.K. Vasudevan, J.J. Petrovic, A comparative overview of molybdenum disilicide composites, Mater. Sci. Eng., A155 (1992) 1-17.

4. J.J. Petrovic, A.K. Vasudevan, Key developments in high temperature structural silicides, Mater. Sci. Eng., A261 (1999) 1-5. 
5. R. Mitra, Mechanical behaviour and oxidation resistance of structural silicides, Int. Mater. Rev., 51 (2006) 13-64.

6. S.A. Maloy, A. H. Heuer, J.J. Lewandowski, T.E. Mitchell, On the slip systems in $\mathrm{MoSi}_{2}$, Acta metal. mater. 40 (1992) 3159-3165.

7. K. Ito, H. Inui, Y. Shirai, M. Yamaguchi, Plastic deformation of $\mathrm{MoSi}_{2}$ single crystals, Philos. Mag. A, 72 (1995) 1075-1097.

8. S.A. Maloy, T.E. Mitchell, A. H. Heuer, High temperature plastic anisotropy in $\mathrm{MoSi}_{2}$ single crystals, Acta metal. mater., 43 (1995) 657-668.

9. K. Ito, T. Yano, T. Nakamoto, M. Moriwaki, H. Inui, M. Yamaguchi, Microstructure and mechanical properties of $\mathrm{MoSi}_{2}$ single crystals and directionally solidifined $\mathrm{MoSi}_{2}$-based alloys, Prog. Mater. Sci., 42 (1997) 193-207.

10. H. Inui, K. Ishikawa, M. Yamaguchi, Effects of alloying elements on plastic deformation of single crystals of $\mathrm{MoSi}_{2}$, Intermet., 8 (2000) 1131-1145.

11. H. Inui, K. Ishikawa, M. Yamaguchi, Creep deformation of single crystals of binary and some ternary $\mathrm{MoSi}_{2}$ with the $\mathrm{C} 11_{\mathrm{b}}$ structure, Intermet., 8 (2000) 1159-1168.

12. P. J. Meschter, D.S. Schwartz, Silicide-matrix materials for high-temperature applications, JOM, 41(11) (1989) 52-55.

13. K. Ito, T. Yano, T. Nakamoto, H. Inui, M. Yamaguchi, Intermet., 4 (1996) S119-S131.

14. R. Gibala, A.K. Ghosh, D.C. Van Aken, D.J. Srolovitz, A. Basu, H. Chang, D.P. Mason, W. Yang, Mater. Sci. Eng., A155 (1992) 147-158.

15. J.B. Berkowitz-Mattuck, P.E. Blackburn, E.J. Felten, The intermediate-temperature oxidation behavior of molybdenum disilicide, Trans. Metall. Soc. AIME, 233 (1965) 1093-1099. 
16. J.B. Berkowitz-Mattuck, M. Rossetti, D.W. Lee, Enhanced oxidation of molybdenum disilicide under tensile stress: relation to pest mechanisms, Metall. Trans., 1 (1970) 479483.

17. P.J. Meschter, Low-temperature oxidation of molybdenum disilicide, Metall. Trans. A, 23A (1992) 1763-1772.

18. F. Zhang, L. Zhang, A. Shan, J. Wu, Oxidation of stoichiometric poly- and singlecrystalline $\mathrm{MoSi}_{2}$ at 773K, Intermet. 14 (2006) 406-411.

19. D. P. Mason, D.C. Van Aken, The effect of microstructural scale on hardness of $\mathrm{MoSi}_{2}-$ $\mathrm{Mo}_{5} \mathrm{Si}_{3}$ eutectics, Scr. Metal. Mater., 28 (1993) 185-189.

20. D. P. Mason, D. C. Van Aken, J. F. Mansfield, On the microstructure and crystallography of directionally solidified $\mathrm{MoSi}_{2}-\mathrm{Mo}_{5} \mathrm{Si}_{3}$ eutectics, Acta metall. mater., 43 (1995) 11891199.

21. D. P. Mason, D.C. Van Aken, On the creep of directionally solidified $\mathrm{MoSi}_{2}-\mathrm{Mo}_{5} \mathrm{Si}_{3}$ eutectics, Acta metall. mater., 43 (1995) 1201-1210.

22. S.Q. Xiao, S.A. Maloy, A.H. Heuer, U. Dahmen, Morphology and interface structure of $\mathrm{Mo}_{5} \mathrm{Si}_{3}$ precipitates in $\mathrm{MoSi}_{2}$, Philos. Mag., 72 (1995) 997-1013.

23. S. Ueno, T. Fukui, R. Tanaka, S. Miura, Y. Mishima, Phase transformation of $\mathrm{MoSi}_{2}$ phase in $\mathrm{MoSi}_{2} / \mathrm{Mo}_{5} \mathrm{Si}_{3}$ eutectic alloy containing Nb, Mater. Trans., 40 (1999) 369-372.

24. K. Fujiwara, Y. Sasai, K. Kishida, H. Inui, Effects of Ternary Additions on the Microstructure of Directionally-Solidified $\mathrm{MoSi}_{2} / \mathrm{Mo}_{5} \mathrm{Si}_{3}$ Eutectic Composites, MRS Symp. Proc., 1516 (2013) 189-194.

25. Y. Sasai, A. Inoue, K. Fujiwara, K. Kishida, H. Inui, Plastic Deformation of Directionally-Solidified $\mathrm{MoSi}_{2} / \mathrm{Mo}_{5} \mathrm{Si}_{3}$ Eutectic Composites, MRS Symp. Proc., 1516 (2013) 195-200. 
26. C.J. McMahon Jr., V. Vitek, The effects of segregated impurity on intergranular fracture energy, Acta Metall., 27 (1979) 507-513.

27. M.L. Jokl, V. Vitek, C.J. McMahon Jr., A microscopic theory of brittle fracture in deformable solids: a relation between ideal work to fracture and plastic work, Acta Metall, 28 (1980) 1479-1488.

28. W. Kurz, D. J. Fisher, Fundamentals of solidification, fourth rev. ed., Trans Tech Publ., Switzerland, 1998.

29. J. LLorca, V.M. Orera, Directionally solidified eutectic cerarmic oxides, Prog. Mater. Sci., 51 (2006) 711-809.

30. D. Yi, Z. Lai, C. Li, O.M. Akselsen, J.H. Ulvensoen, Ternary alloying study of $\mathrm{MoSi}_{2}$, Metall. Mater. Trans. A, 29A (1998) 119-129.

31. P. Villars, H. Okamoto, K. Cenzual (Eds.), ASM Alloy Phase Diagram Database, ASM Int., Materials Park, 2006-2013.

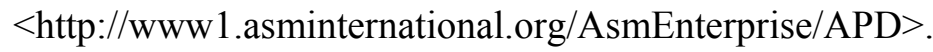

32. E. Teatum, K. Gschneidner, Jr., J. Waber, Los Alamos Sci. Lab. Rep. LA-2345, U.S. Dep Commer, Washington D.C., 1960.

33. J.H. Schneibel, C.J. Rawn, T.R. Watkins, E.A. Payzant, Thermal expansion anisotropy of ternary molybdenum silicides based on $\mathrm{Mo}_{5} \mathrm{Si}_{3}$, Phys. Rev. B, 65 (2002) 134112-1-5.

34. J.H. van der Merwe, G.J. Shiflet, P.M. Stoop, Structural ledges in interphase boundaries, Metall. Trans. A, 22A (1991) 1165-1175.

35. Y. Mou, Intrinsic ledges at interphase boundaries and the crystallography of precipitate plates, Metall. Trans. A, 25A (1994) 1905-1915.

36. O. Thomas, J.P. Senateur, R. Madar, O. Laborde, E. Rosencher, Molybdenum disilicide: crystal growth, thermal expansion and resistivity, Solid State Commun., 55 (1985) 629632. 
37. F. Chu, D.J. Thoma, K. McClellan, P. Peralta, Y. He, Synthesis and properties of $\mathrm{Mo}_{5} \mathrm{Si}_{3}$ single crystals, Intermet., 7 (1999) 611-620.

38. C. Zener, Kinetics of the Decomposition of Austenite, Trans. A.I.M.E., 167 (1946) 550583. 
Table 1. Chemical compositions and lattice constants for binary and ternary $\mathrm{MoSi}_{2} / \mathrm{Mo}_{5} \mathrm{Si}_{3}$ eutectic composites alloyed with the type-1 elements.

\begin{tabular}{|c|c|c|c|c|c|c|c|}
\hline \multirow{2}{*}{$\begin{array}{l}\text { Ternary } \\
\text { element }\end{array}$} & \multirow{2}{*}{$\begin{array}{l}\text { Amount } \\
\text { of } \\
\text { addition }\end{array}$} & \multirow{2}{*}{ Phase } & \multicolumn{3}{|c|}{ Chemical composition (at.\%) } & \multicolumn{2}{|c|}{ Lattice constants (nm) } \\
\hline & & & Mo & $\mathrm{Si}$ & $X$ & $a$ & C \\
\hline \multirow[t]{2}{*}{ Binary } & \multirow[t]{2}{*}{-} & $\mathrm{MoSi}_{2}$ & 35.2 & 64.8 & - & 0.321 & 0.785 \\
\hline & & $\mathrm{Mo}_{5} \mathrm{Si}_{3}$ & 63.2 & 36.8 & - & 0.966 & 0.490 \\
\hline \multirow{4}{*}{$\begin{array}{l}\mathrm{Ti} \\
\text { atomic } \\
\text { radius: } \\
0.146 \mathrm{~nm}\end{array}$} & \multirow[t]{2}{*}{1} & $\mathrm{MoSi}_{2}$ & 35.7 & 64.3 & 0.0 & 0.321 & 0.785 \\
\hline & & $\mathrm{Mo}_{5} \mathrm{Si}_{3}$ & 61.4 & 36.6 & 2.0 & 0.966 & 0.490 \\
\hline & \multirow[t]{2}{*}{5} & $\mathrm{MoSi}_{2}$ & 35.6 & 64.4 & 0.1 & 0.321 & 0.785 \\
\hline & & $\mathrm{Mo}_{5} \mathrm{Si}_{3}$ & 53.9 & 36.8 & 9.3 & 0.968 & 0.490 \\
\hline \multirow{4}{*}{$\begin{array}{l}\mathrm{V} \\
\text { atomic } \\
\text { radius: } \\
0.135 \mathrm{~nm}\end{array}$} & \multirow[t]{2}{*}{2} & $\mathrm{MoSi}_{2}$ & 35.2 & 64.6 & 0.2 & 0.321 & 0.785 \\
\hline & & $\mathrm{Mo}_{5} \mathrm{Si}_{3}$ & 58.7 & 37.1 & 4.2 & 0.964 & 0.488 \\
\hline & \multirow[t]{2}{*}{5} & $\mathrm{MoSi}_{2}$ & 35.0 & 64.6 & 0.4 & 0.321 & 0.785 \\
\hline & & $\mathrm{Mo}_{5} \mathrm{Si}_{3}$ & 53.6 & 36.4 & 10.0 & 0.963 & 0.487 \\
\hline \multirow{6}{*}{$\begin{array}{l}\mathrm{Cr} \\
\text { atomic } \\
\text { radius: } \\
0.128 \mathrm{~nm}\end{array}$} & \multirow[t]{2}{*}{1} & $\mathrm{MoSi}_{2}$ & 35.3 & 64.7 & 0.0 & 0.321 & 0.785 \\
\hline & & $\mathrm{Mo}_{5} \mathrm{Si}_{3}$ & 60.3 & 37.3 & 2.4 & 0.965 & 0.489 \\
\hline & \multirow[t]{2}{*}{2} & $\mathrm{MoSi}_{2}$ & 35.6 & 64.4 & 0.0 & 0.321 & 0.785 \\
\hline & & $\mathrm{Mo}_{5} \mathrm{Si}_{3}$ & 59.3 & 37.6 & 3.1 & 0.964 & 0.488 \\
\hline & \multirow[t]{2}{*}{5} & $\mathrm{MoSi}_{2}$ & 35.3 & 64.7 & 0.0 & 0.321 & 0.785 \\
\hline & & $\mathrm{Mo}_{5} \mathrm{Si}_{3}$ & 54.5 & 36.9 & 8.6 & 0.963 & 0.485 \\
\hline \multirow{6}{*}{$\begin{array}{l}\mathrm{Nb} \\
\text { atomic } \\
\text { radius: } \\
0.147 \mathrm{~nm}\end{array}$} & \multirow[t]{2}{*}{1} & $\mathrm{MoSi}_{2}$ & 36.3 & 62.8 & 0.8 & 0.321 & 0.785 \\
\hline & & $\mathrm{Mo}_{5} \mathrm{Si}_{3}$ & 59.1 & 38.4 & 2.4 & 0.967 & 0.490 \\
\hline & \multirow[t]{2}{*}{2} & $\mathrm{MoSi}_{2}$ & 36.5 & 62.5 & 1.1 & 0.321 & 0.785 \\
\hline & & $\mathrm{Mo}_{5} \mathrm{Si}_{3}$ & 57.7 & 37.2 & 5.1 & 0.968 & 0.491 \\
\hline & \multirow[t]{2}{*}{5} & $\mathrm{MoSi}_{2}$ & 34.4 & 64.1 & 1.5 & 0.321 & 0.786 \\
\hline & & $\mathrm{Mo}_{5} \mathrm{Si}_{3}$ & 52.8 & 37.0 & 10.2 & 0.971 & 0.492 \\
\hline \multirow{4}{*}{$\begin{array}{l}\mathrm{Ta} \\
\text { atomic } \\
\text { radius: } \\
0.147 \mathrm{~nm}\end{array}$} & \multirow[t]{2}{*}{2} & $\mathrm{MoSi}_{2}$ & 35.3 & 64.7 & 0.0 & 0.321 & 0.785 \\
\hline & & $\mathrm{Mo}_{5} \mathrm{Si}_{3}$ & 57.6 & 40.7 & 1.6 & 0.968 & 0.491 \\
\hline & \multirow[t]{2}{*}{5} & $\mathrm{MoSi}_{2}$ & 34.7 & 65.3 & 0.0 & 0.321 & 0.785 \\
\hline & & $\mathrm{Mo}_{5} \mathrm{Si}_{3}$ & 48.7 & 45.8 & 5.5 & 0.971 & 0.493 \\
\hline \multirow{6}{*}{$\begin{array}{l}\mathrm{W} \\
\text { atomic } \\
\text { radius: } \\
0.141 \mathrm{~nm}\end{array}$} & \multirow[t]{2}{*}{1} & $\mathrm{MoSi}_{2}$ & 35.4 & 58.7 & 5.8 & 0.321 & 0.786 \\
\hline & & $\mathrm{Mo}_{5} \mathrm{Si}_{3}$ & 57.1 & 37.8 & 5.1 & 0.966 & 0.490 \\
\hline & \multirow[t]{2}{*}{2} & $\mathrm{MoSi}_{2}$ & 34.7 & 59.3 & 6.0 & 0.321 & 0.786 \\
\hline & & $\mathrm{Mo}_{5} \mathrm{Si}_{3}$ & 59.4 & 34.1 & 6.5 & 0.966 & 0.490 \\
\hline & \multirow[t]{2}{*}{5} & $\mathrm{MoSi}_{2}$ & 33.0 & 58.6 & 8.4 & 0.321 & 0.786 \\
\hline & & $\mathrm{Mo}_{5} \mathrm{Si}_{3}$ & 55.7 & 32.2 & 12.1 & 0.965 & 0.491 \\
\hline
\end{tabular}


Table 2. Chemical compositions for ternary $\mathrm{MoSi}_{2} / \mathrm{Mo}_{5} \mathrm{Si}_{3}$ eutectic composites alloyed with the type-2 elements of $\mathrm{Fe}, \mathrm{Co}, \mathrm{Ni}$ and Ir.

\begin{tabular}{|c|c|c|c|c|c|}
\hline \multirow{2}{*}{$\begin{array}{l}\text { Ternary } \\
\text { element }\end{array}$} & \multirow{2}{*}{$\begin{array}{l}\text { Amount } \\
\text { of } \\
\text { addition }\end{array}$} & \multirow{2}{*}{ Phase } & \multicolumn{3}{|c|}{ Chemical composition (at.\%) } \\
\hline & & & Mo & $\mathrm{Si}$ & $\mathrm{X}$ \\
\hline \multirow[t]{3}{*}{$\mathrm{Fe}$} & \multirow[t]{3}{*}{2} & $\mathrm{MoSi}_{2}$ & 35.4 & 64.6 & 0.0 \\
\hline & & $\mathrm{Mo}_{5} \mathrm{Si}_{3}$ & 61.1 & 37.1 & 1.8 \\
\hline & & Ternary & 35.3 & 38.0 & 26.7 \\
\hline \multirow[t]{3}{*}{ Co } & \multirow[t]{3}{*}{2} & $\mathrm{MoSi}_{2}$ & 35.7 & 64.3 & 0.0 \\
\hline & & $\mathrm{Mo}_{5} \mathrm{Si}_{3}$ & 62.3 & 37.1 & 0.6 \\
\hline & & Ternary & 33.0 & 30.1 & 36.9 \\
\hline \multirow[t]{3}{*}{$\mathrm{Ni}$} & \multirow[t]{3}{*}{2} & $\mathrm{MoSi}_{2}$ & 35.7 & 64.3 & 0.0 \\
\hline & & $\mathrm{Mo}_{5} \mathrm{Si}_{3}$ & 62.7 & 36.9 & 0.5 \\
\hline & & Ternary & 35.0 & 32.4 & 32.6 \\
\hline \multirow[t]{3}{*}{ Ir } & \multirow[t]{3}{*}{0.2} & $\mathrm{MoSi}_{2}$ & 36.4 & 62.2 & 1.4 \\
\hline & & $\mathrm{Mo}_{5} \mathrm{Si}_{3}$ & 62.7 & 34.6 & 2.7 \\
\hline & & Ternary & 5.8 & 43.0 & 51.2 \\
\hline
\end{tabular}




\section{Figure captions}

Figure 1. (a-i) SEM backscattered electron images of three mutually orthogonal sections of DS ingots of binary $\mathrm{MoSi}_{2} / \mathrm{Mo}_{5} \mathrm{Si}_{3}$ eutectic composites grown at growth rates of (a-c) 10 $\mathrm{mm} / \mathrm{h},(\mathrm{d}-\mathrm{f}) 50 \mathrm{~mm} / \mathrm{h}$ and (g-i) $200 \mathrm{~mm} / \mathrm{h}$. (j-l) Schematic illustration of two types of interfaces between $\mathrm{MoSi}_{2}$ and $\mathrm{Mo}_{5} \mathrm{Si}_{3}$ phases in the eutectic compostites.

Figure 2 Schematic illustrations of three types of interfaces and corresponding lattice misfits in $\mathrm{MoSi}_{2} / \mathrm{Mo}_{5} \mathrm{Si}_{3}$ eutectic composites.

Figure 3. Atomic resolution HAADF-STEM images and a selected area electron diffraction patterns taken from the interface region in a binary DS ingot grown at a growth rate of 10 $\mathrm{mm} / \mathrm{h}$ projected along (a),(b) $[001]_{\mathrm{Mo5Si} 3}$ and (c),(d) $[110]_{\mathrm{MoSi} 2} / /[1 \overline{1} 0]_{\mathrm{Mo5Si3}}$.

Figure 4. SEM backscattered electron images of cross sections of DS $\mathrm{MoSi}_{2} / \mathrm{Mo}_{5} \mathrm{Si}_{3}$ eutectic composites alloyed with (a) 5 at.\% $\mathrm{Nb}$, (b) 5 at.\% Ta and (c) 5 at.\% of $\mathrm{W}$ grown at a growth rate of $10 \mathrm{~mm} / \mathrm{h}$.

Figure 5. SEM backscattered electron images of cross sections of DS $\mathrm{MoSi}_{2} / \mathrm{Mo}_{5} \mathrm{Si}_{3}$ eutectic composites alloyed with (a) 1 at.\% Ti, (b) 5 at.\% Ti, (c) 2 at.\% V, (d) 5 at.\% V, (e) 1 at.\% Cr, (f) 5 at.\% Cr grown at a growth rate of $10 \mathrm{~mm} / \mathrm{h}$ and (g) 1 at. $\%$ Cr grown at a growth rate of 2 $\mathrm{mm} / \mathrm{h}$.

Figure 6. SEM backscattered electron images of longitudinal sections of DS $\mathrm{MoSi}_{2} / \mathrm{Mo}_{5} \mathrm{Si}_{3}$ eutectic composites alloyed with (a) 5 at.\% V, (b) 5 at.\% Ta and (c) 2 at.\% W grown at a growth rate of $10 \mathrm{~mm} / \mathrm{h}$.

Figure 7. Variations of three types of the lattice misfits as a function of the total amount of ternary addition to the DS ingots of the $\mathrm{MoSi}_{2} / \mathrm{Mo}_{5} \mathrm{Si}_{3}$ eutectic composites. (a) Misfit A, (b) misfit B and (c) misfit C. 
Figure 8. SEM backscattered electron images of cross sections of DS $\mathrm{MoSi}_{2} / \mathrm{Mo}_{5} \mathrm{Si}_{3}$ eutectic composites alloyed with (a) 2 at.\% Fe, (b) 2 at.\% Co, (c) 2 at.\% Ni, (d) 0.2 at.\% Ir, (e,f) 2 at.\% B and (g,h) 1 at.\% $\mathrm{C}$ grown at a growth rate of $10 \mathrm{~mm} / \mathrm{h}$.

Figure 9. SEM backscattered electron images of three mutually orthogonal sections of DS $\mathrm{MoSi}_{2} / \mathrm{Mo}_{5} \mathrm{Si}_{3}$ eutectic composites alloyed with (a-c) 0.1 at.\% Co, (d-f) 0.16 at.\% (300 wt.ppm) B and (g-i) 0.15 at.\% (300 wt.ppm) C grown at a growth rate of $10 \mathrm{~mm} / \mathrm{h}$. Figure 10. Segregation behavior at (a) Interface I and (b,c,d) interface II interfaces in DS $\mathrm{MoSi}_{2} / \mathrm{Mo}_{5} \mathrm{Si}_{3}$ eutectic composites alloyed with (a,b) 0.5 at.\% $\mathrm{Co}$, (c) 0.5 at.\% $\mathrm{Ni}$ and (d) 0.2 at. $\%$ Ir.

Figure 11. (a) An atomic resolution HAADF-STEM image taken from the interface I in a DS ingot with 0.5 at.\% $\mathrm{Ni}$ grown at a growth rate of $10 \mathrm{~mm} / \mathrm{h}$ projected along $[110]_{\mathrm{MoSi} 2} / /[1 \overline{1} 0]_{\mathrm{Mo5Si3}}$ and (b) segregation behavior at the ledge and terrace part of the interface I marked in (a).

Figure 12. Schematic illustration of macroscopic strain accommodation at interface I in the $\mathrm{MoSi}_{2} / \mathrm{Mo}_{5} \mathrm{Si}_{3} \mathrm{DS}$ eutectic composites.

Figure 13. Conditions for the macroscopic strain accommodation at the interface I estimated for $\mathrm{MoSi}_{2} / \mathrm{Mo}_{5} \mathrm{Si}_{3}$ DS ingots of (a) binary, (b) 5 at.\% V-alloyed and (c) 5 at.\% Ta-alloyed materials. 


\section{Figure 1}

$(1 \overline{10})_{\mathrm{MoSt}_{2}} / /(001)_{\mathrm{Mos} S i s}$

$(110)_{\mathrm{MoSi}} / /(1 \overline{1} 0)_{\mathrm{Mos} S \mathrm{si}}$

$(001)_{\text {Mosiz }} / /(110)_{\text {Mos Sis }}$

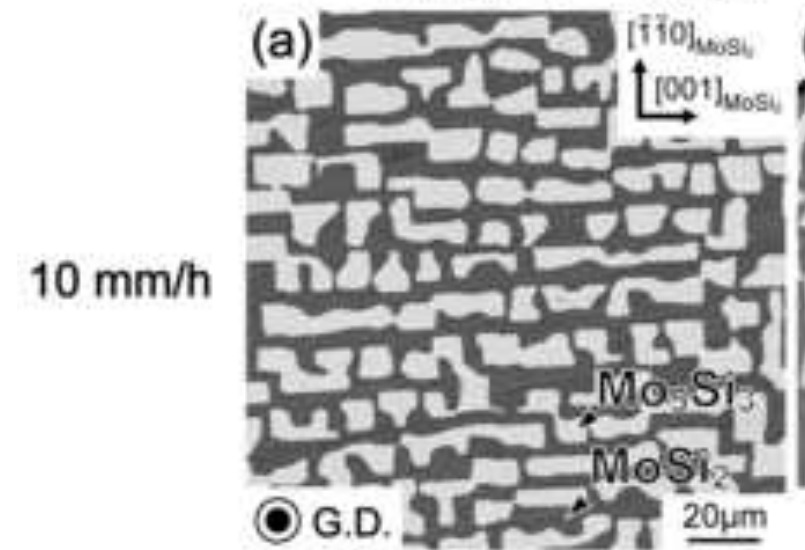

(b) I IV /

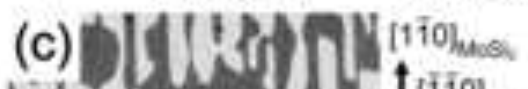

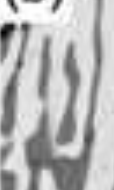

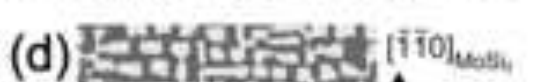

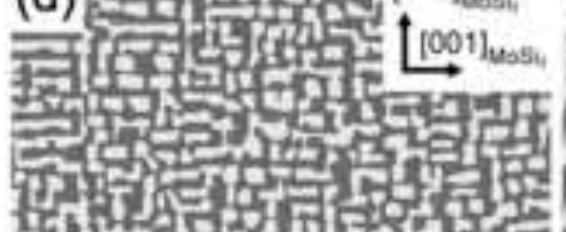

f G.D.

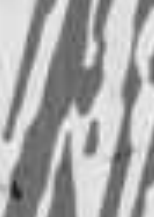

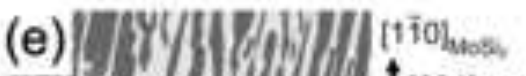

$50 \mathrm{~mm} / \mathrm{h}$

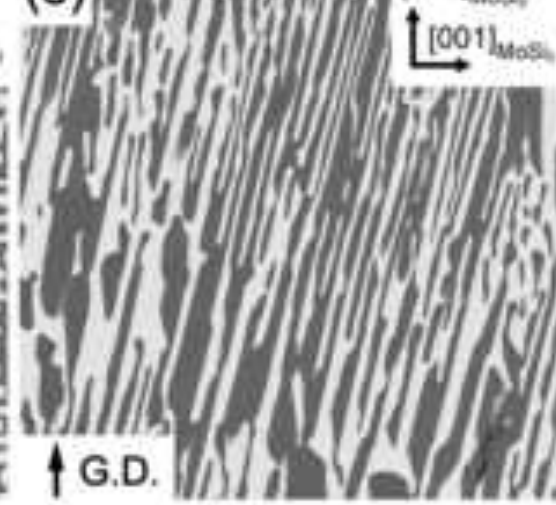

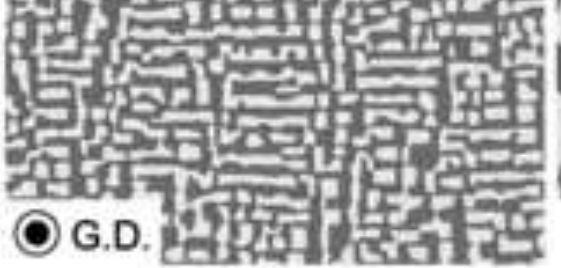
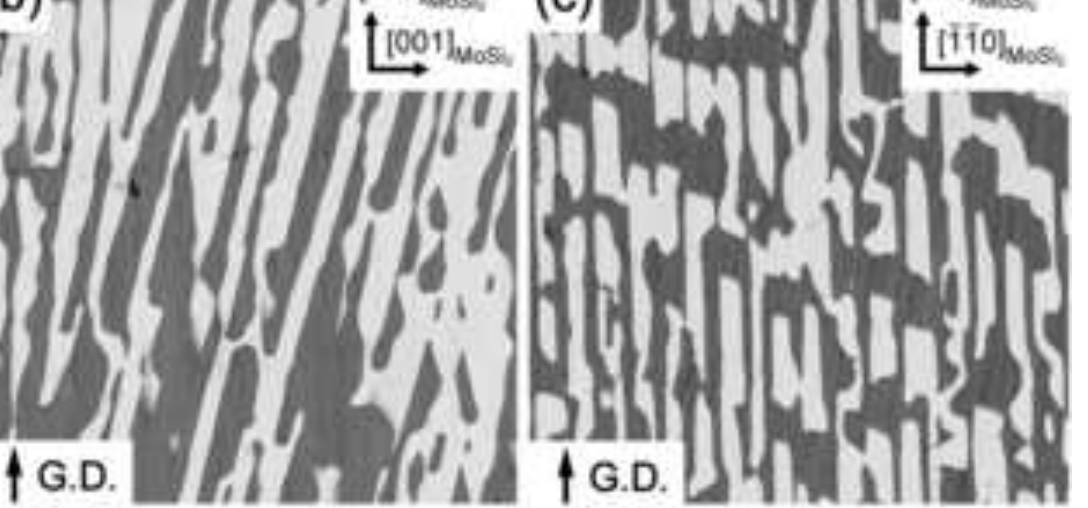

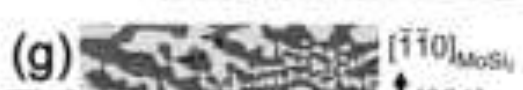

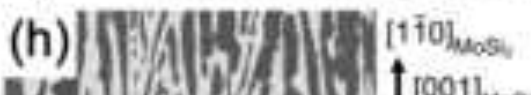

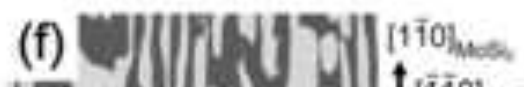
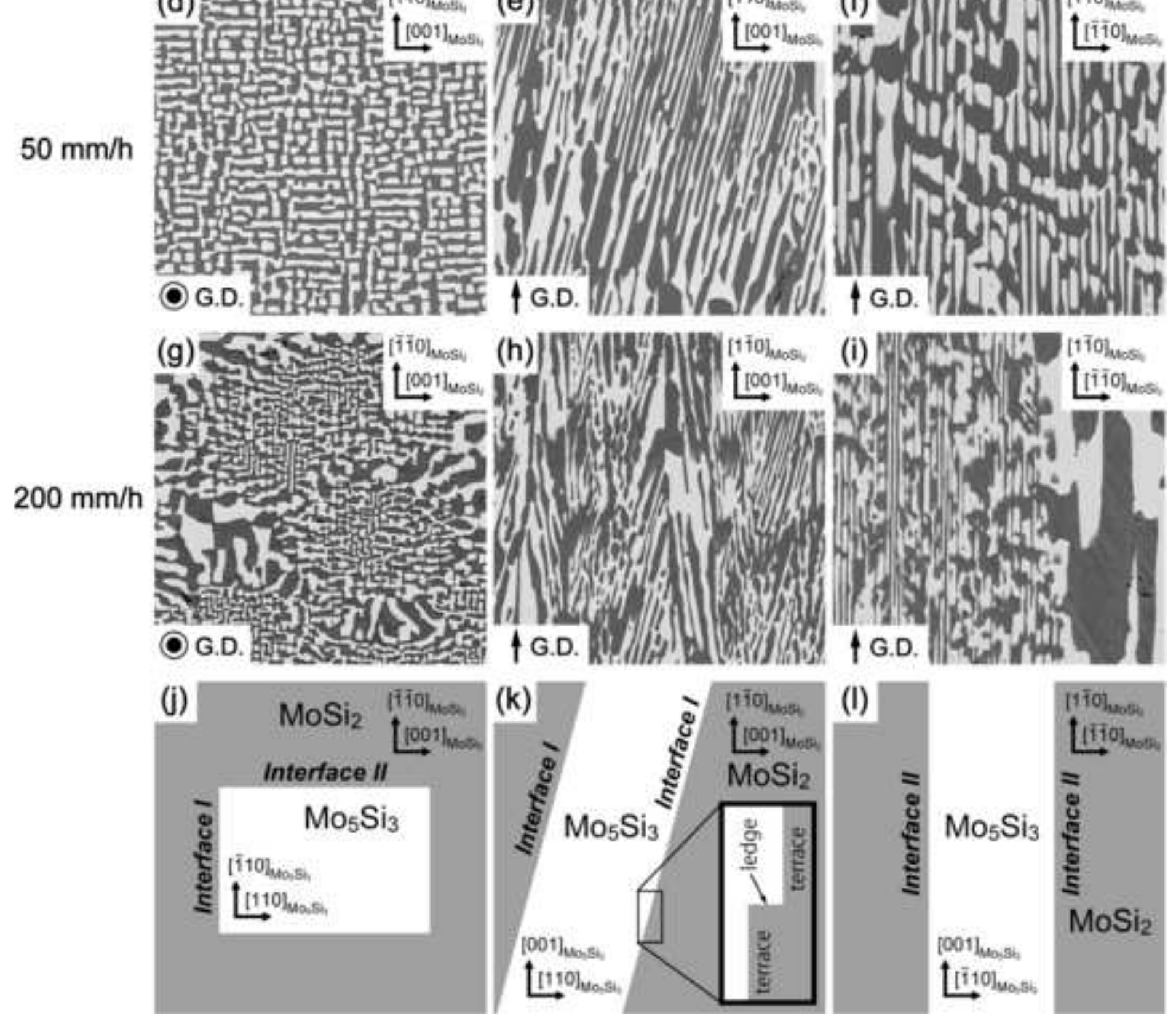

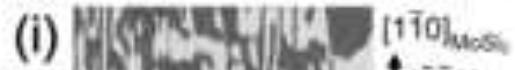

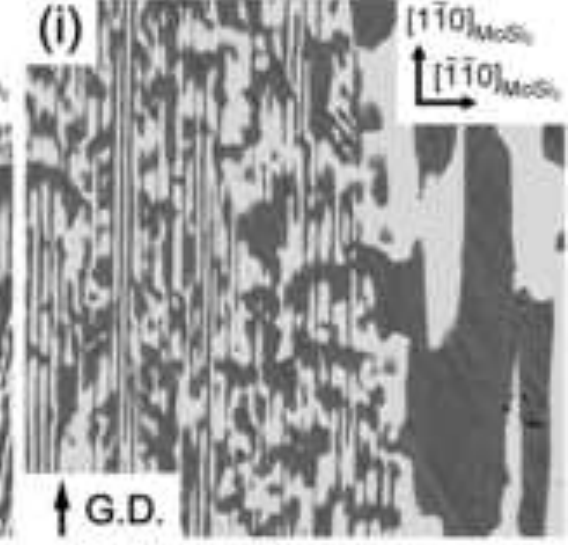




\section{Figure 2}

(a) Interface I (terrace part) Misfit A
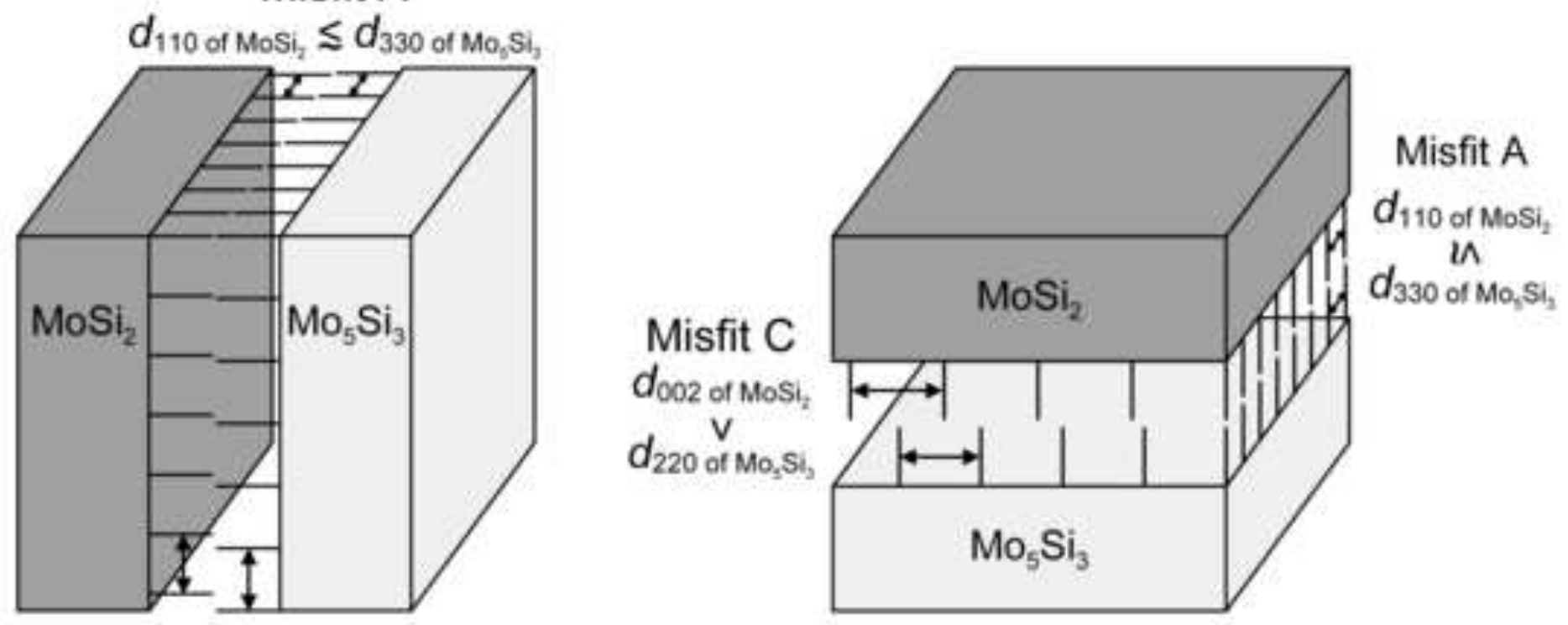

Misfit B

$d_{110 \text { of } \mathrm{MoSi}_{2}<d_{002} \text { of } \mathrm{Mo}_{3} \mathrm{Si}_{2}}$

(c) Interface II

(b) Interface I (ledge part)

Misfit C
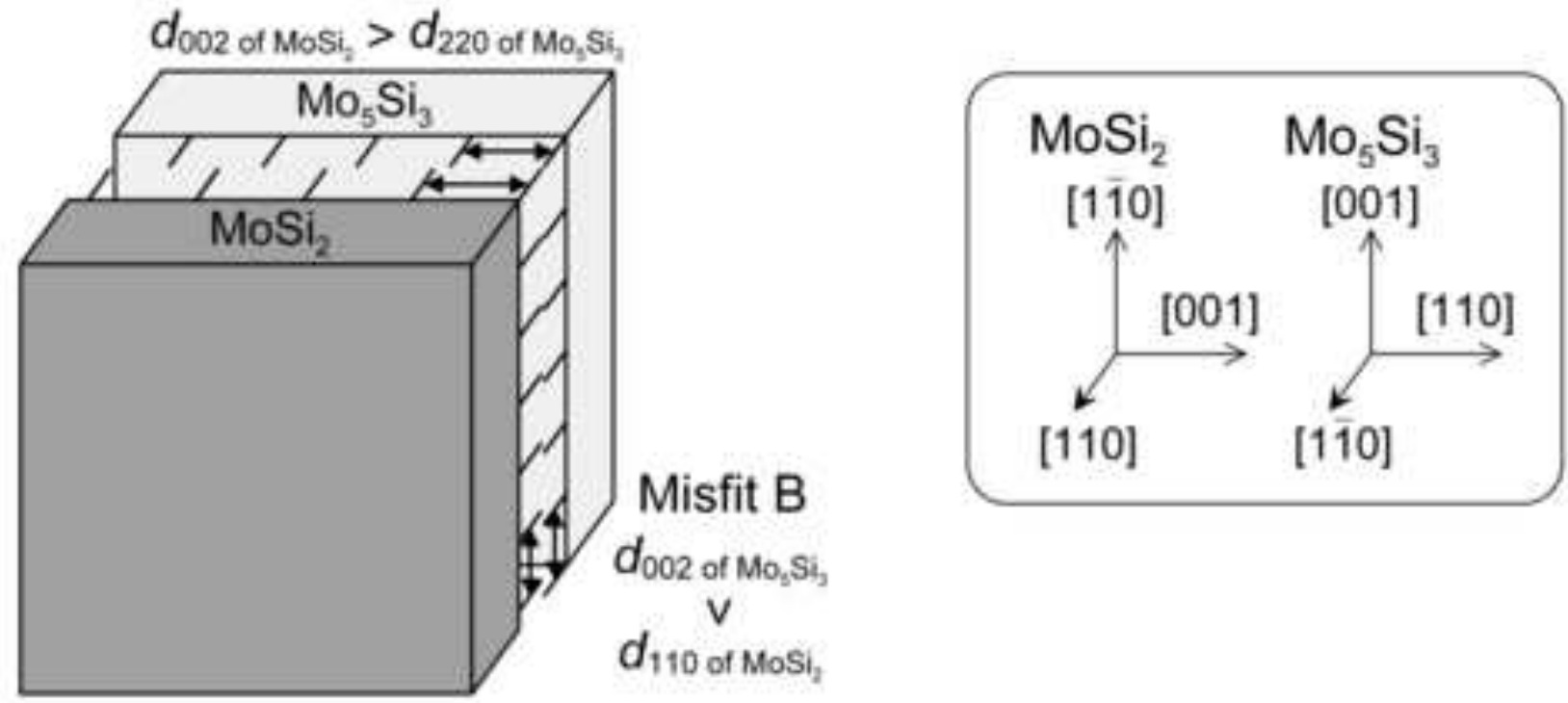

$d_{002 \text { of } \mathrm{MO}_{3} \mathrm{Si}_{3}}$ 


\section{Figure 3}

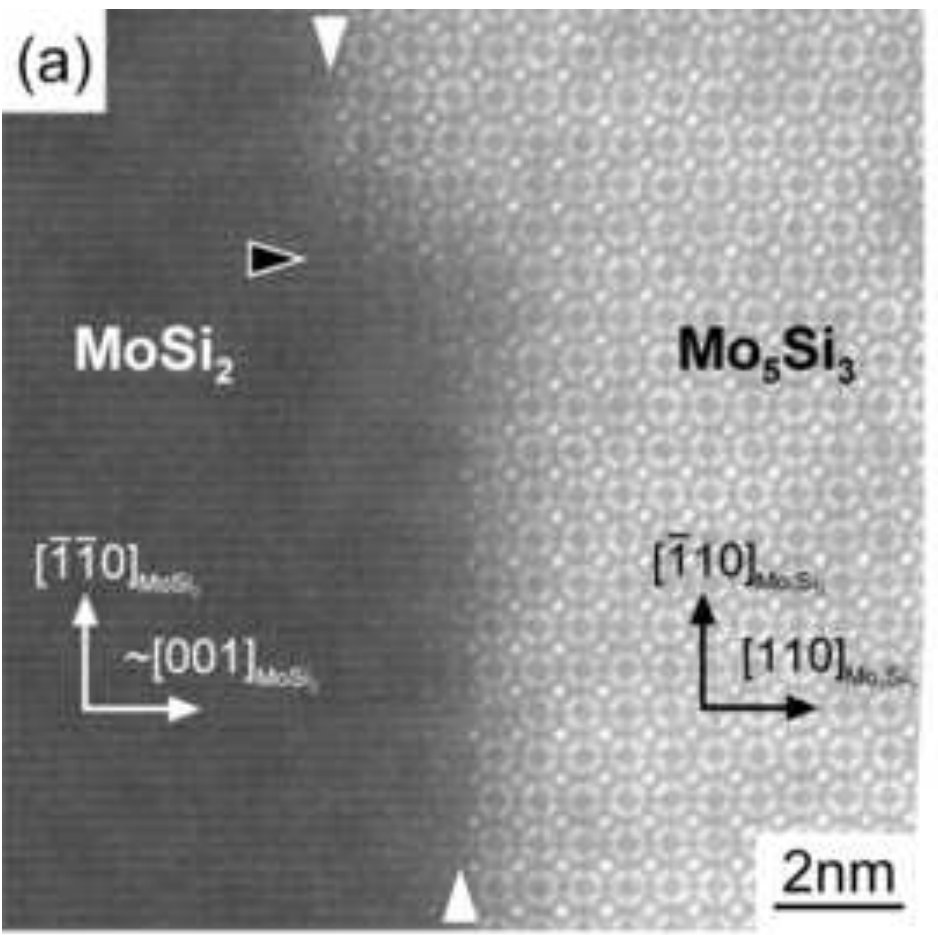

(b)
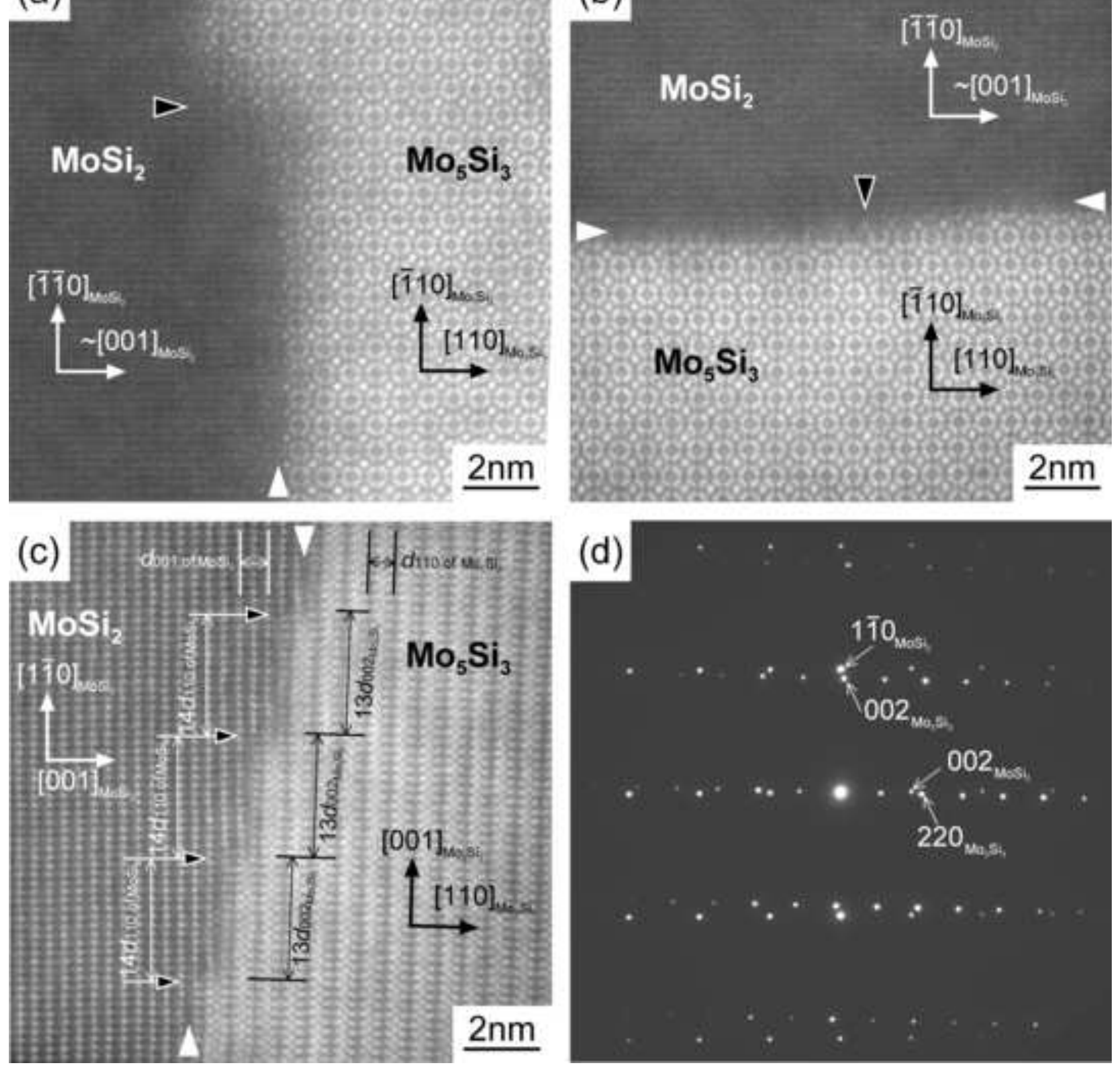


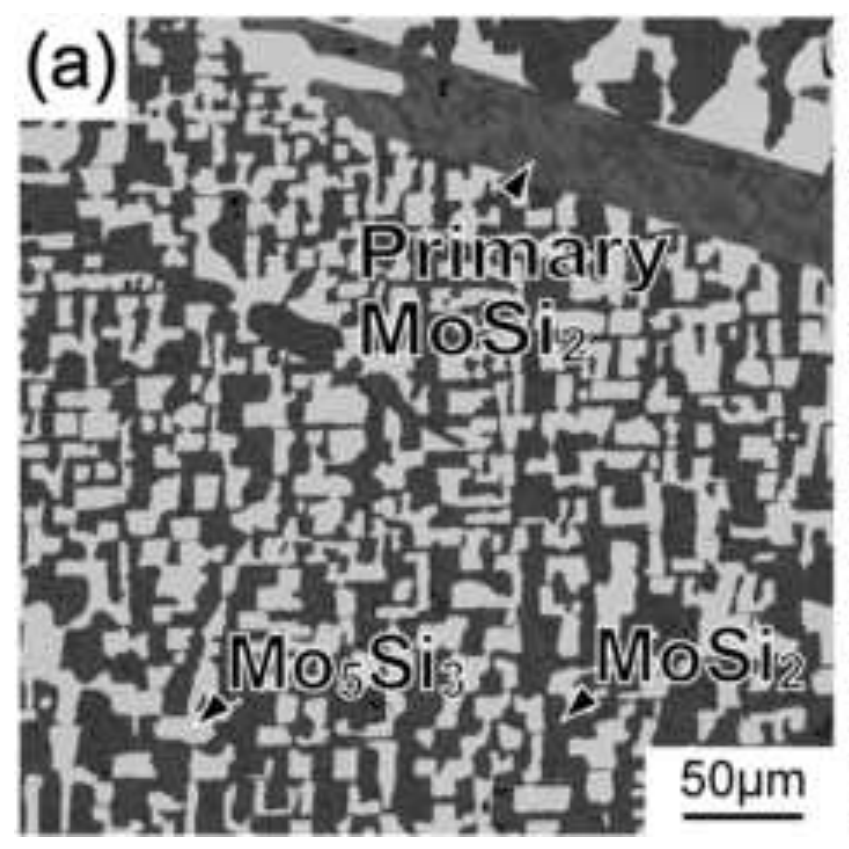

(b)

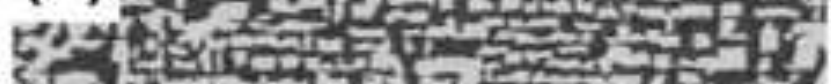
If

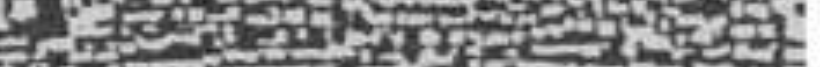
escrint क्रे 푼,

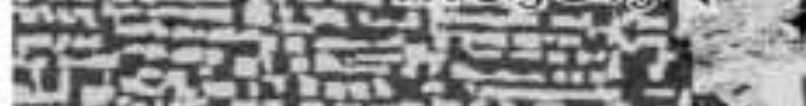

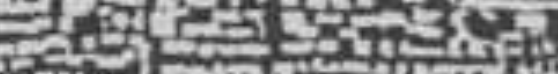
Lum

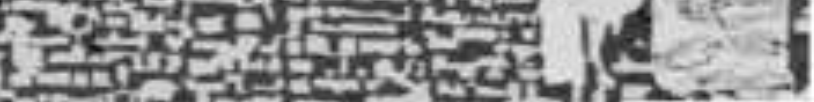

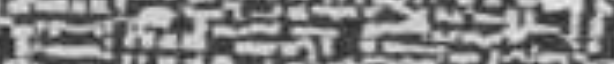

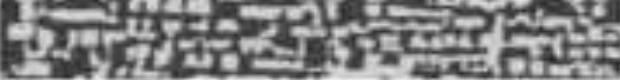

(C) 15. r. of

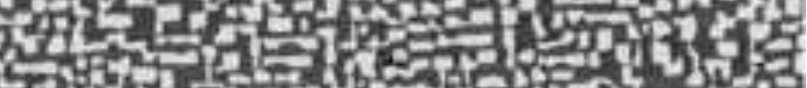
530 . 4 int

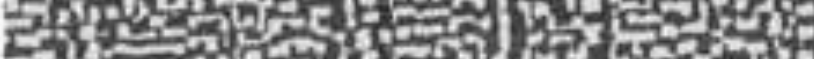

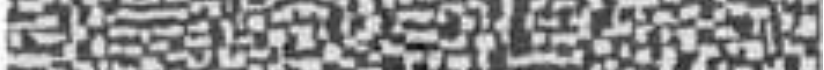

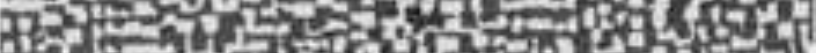
C.

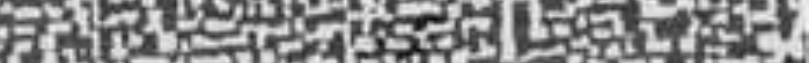

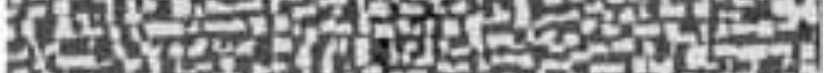

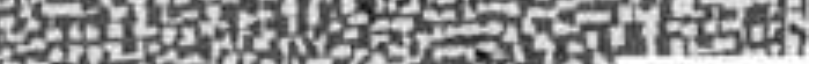

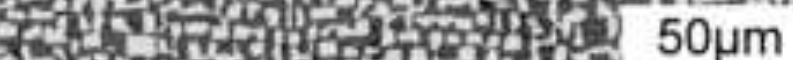

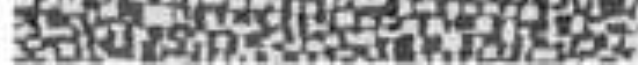




\section{Figure 5}

(a)

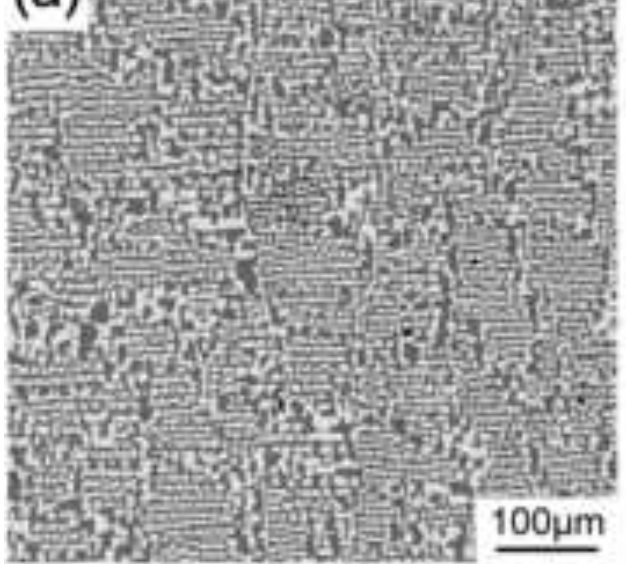

(c)

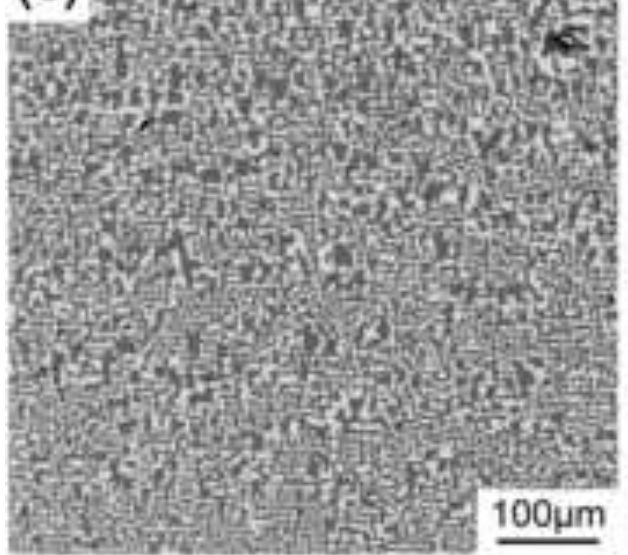

(e)

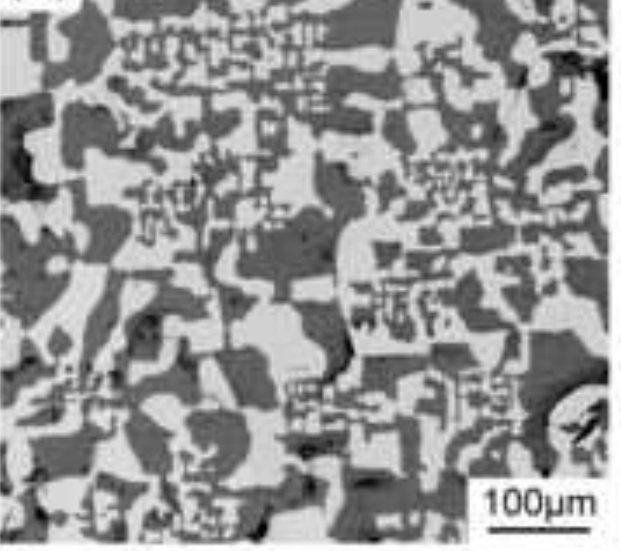

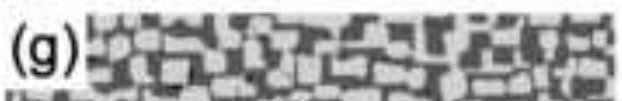
5 8 1.

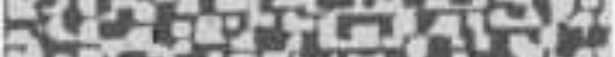

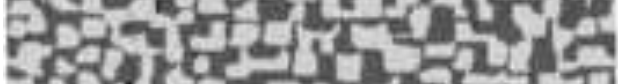

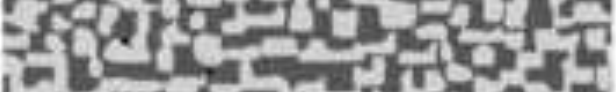

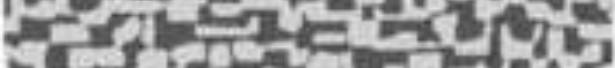
n.

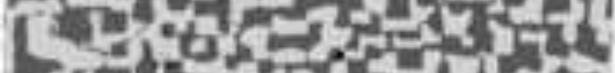

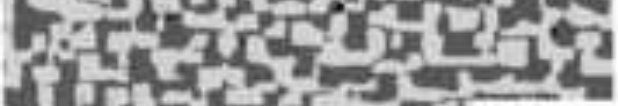

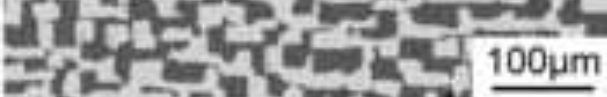
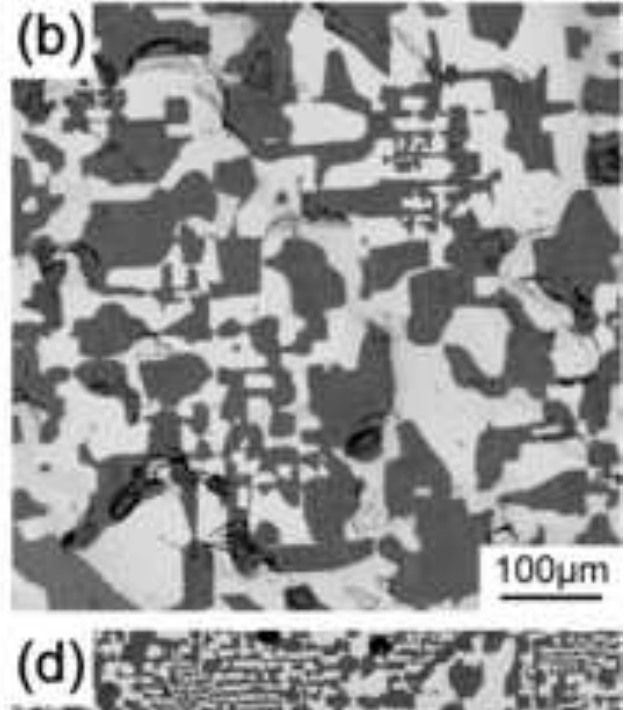

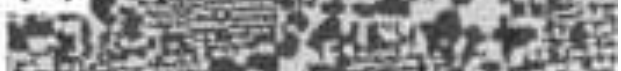
5 s.

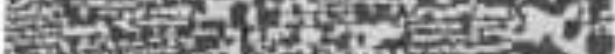

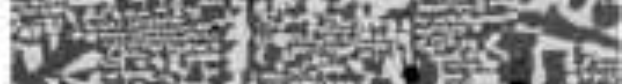
-

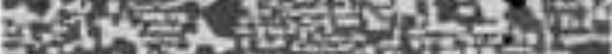

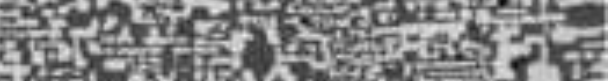

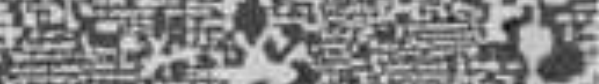

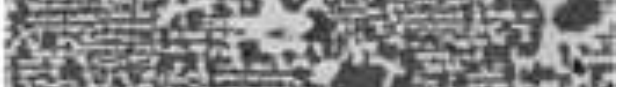

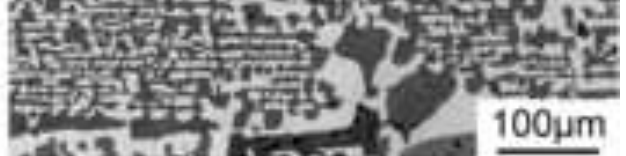

(f)
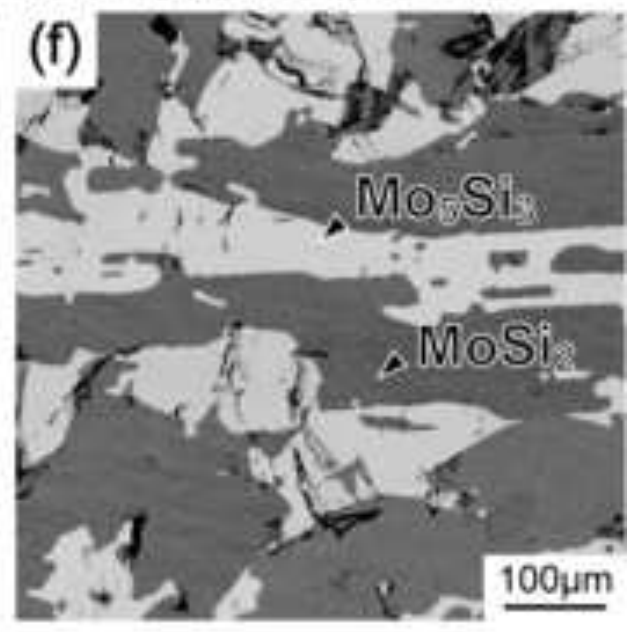


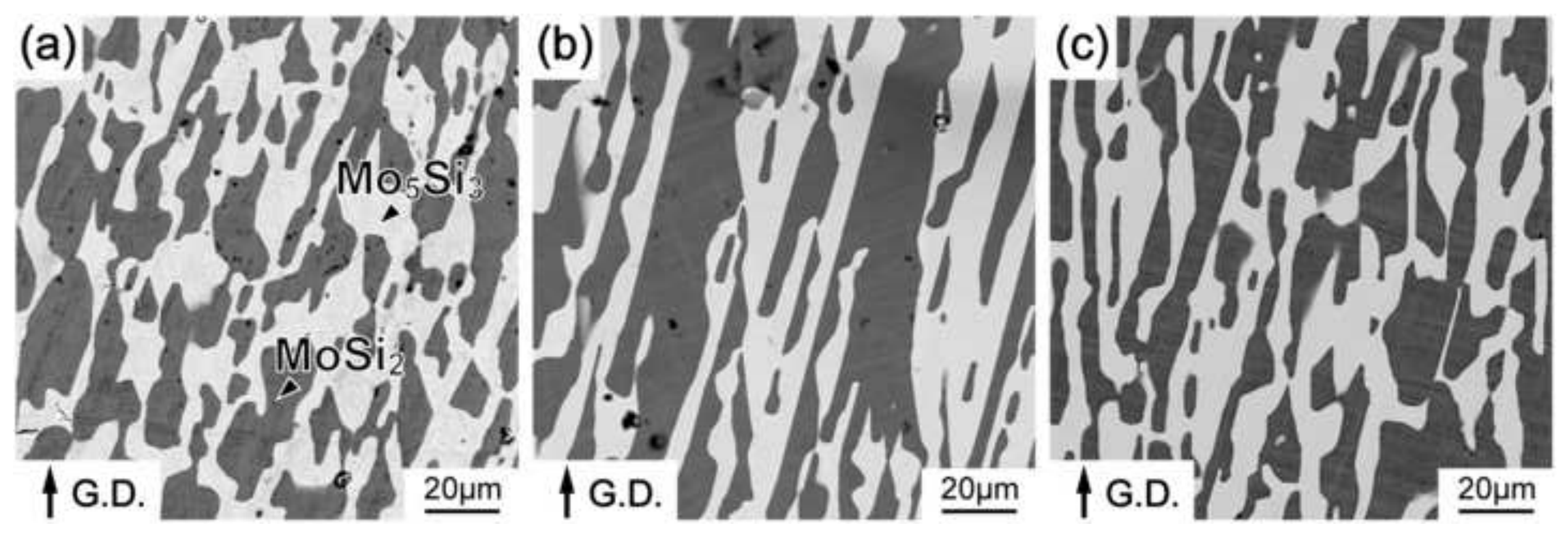



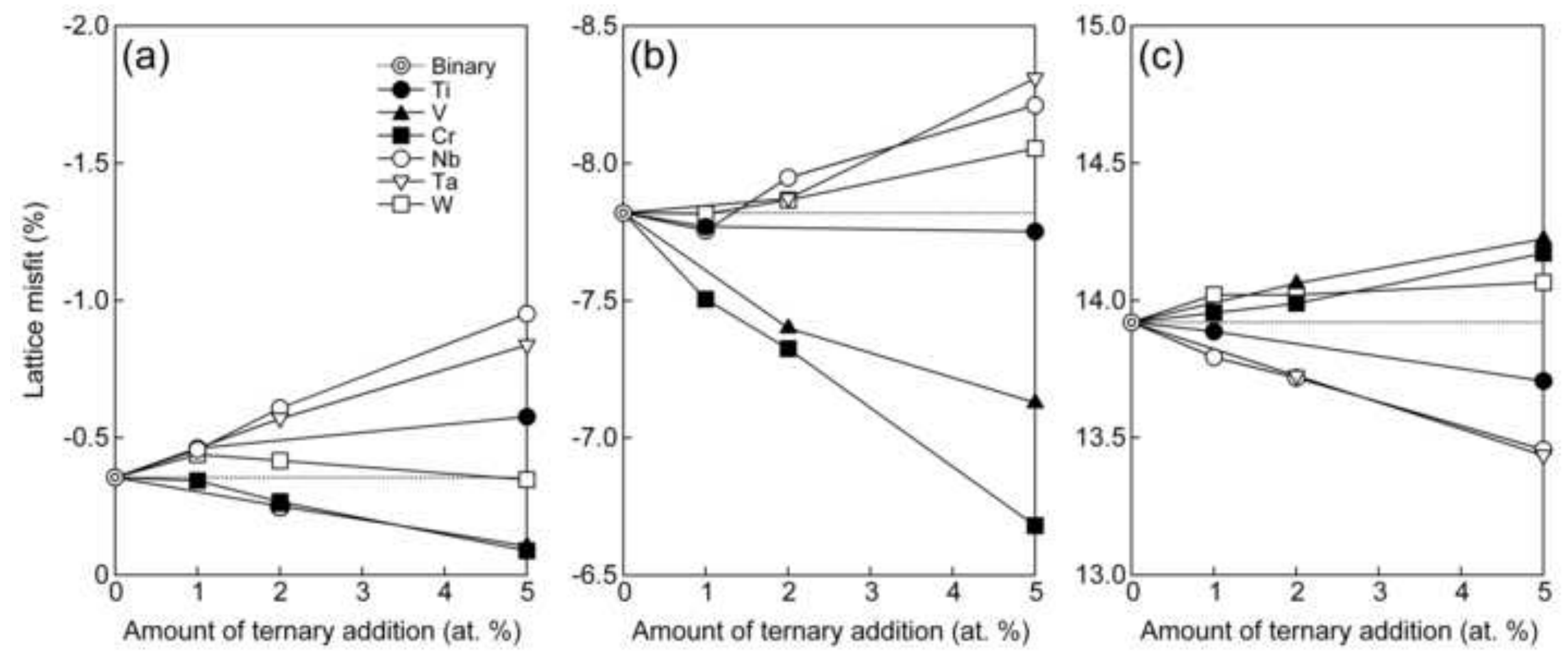

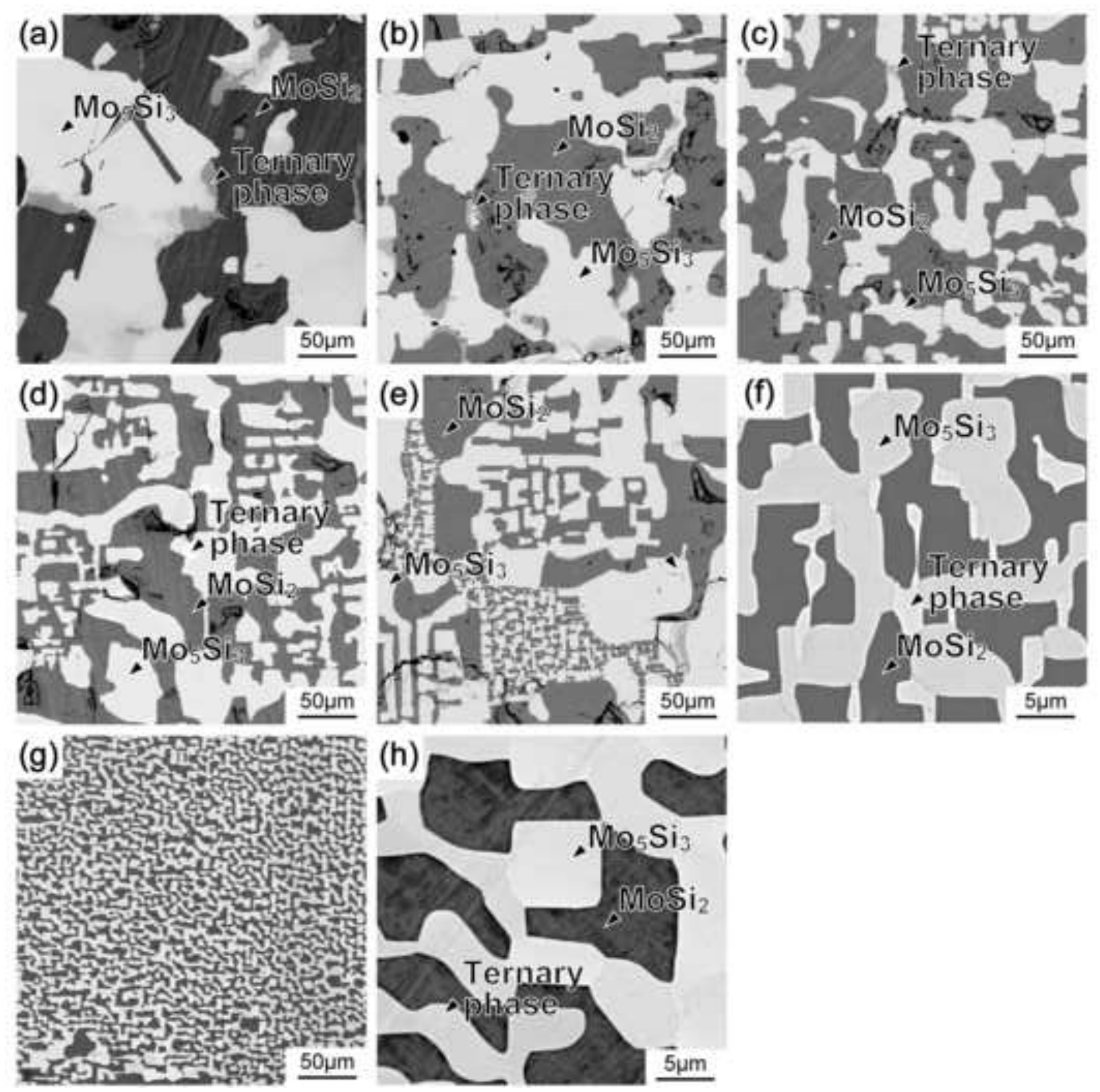
$(1 \overline{1} 0)_{\text {Mosiz }} / /(001)_{\text {MosSis }}$

$(110)_{\text {Mosiz }} / /(1 \overline{10})_{\text {MosSis }} \quad(001)_{\text {MoSiz }_{2}} / /(110)_{\text {Mos Sis }_{3}}$

(a) तitic

triolum

(b)

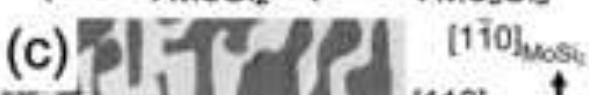

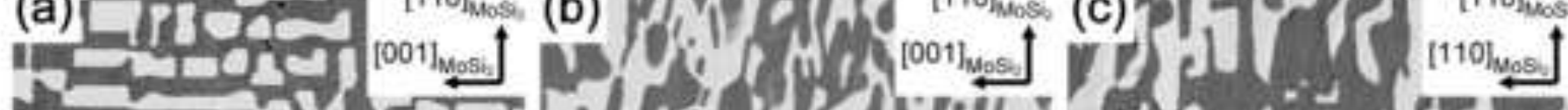

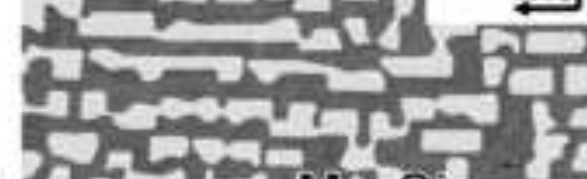

0.1 at. $\%$ Co

列

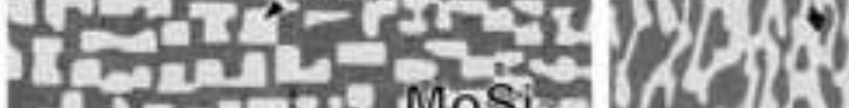

(1)

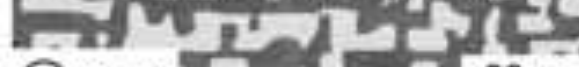

O G.D. ISLI

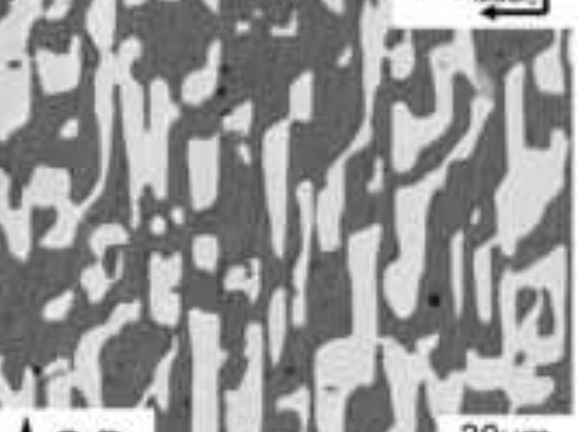

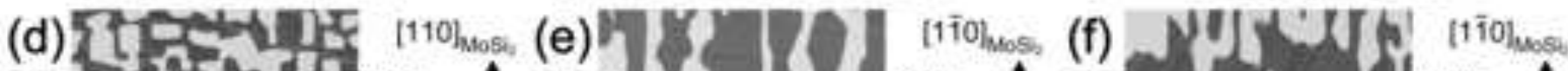

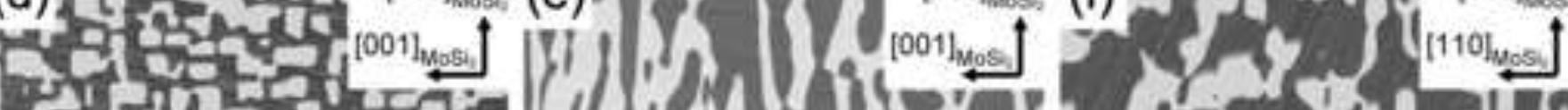

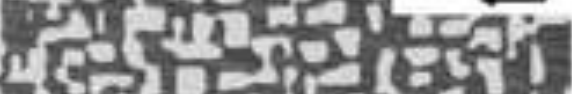

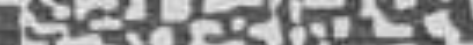

0.16 at. \% B

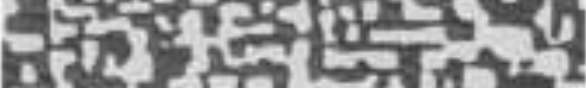

A

Aี

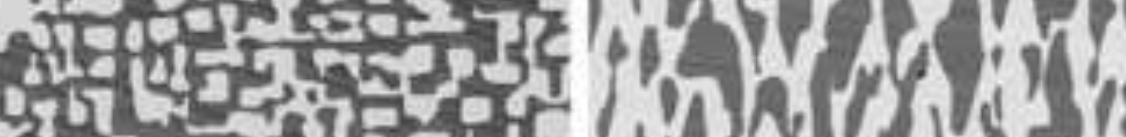

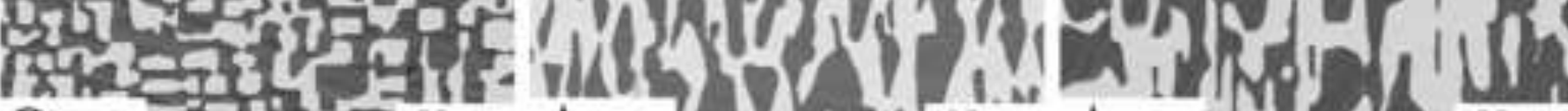

OG.D.

(g) - If The

0.15 at. \% C

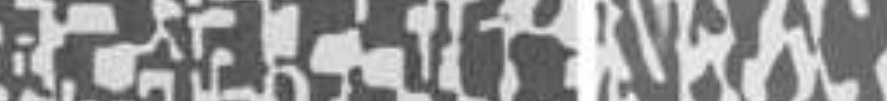

if

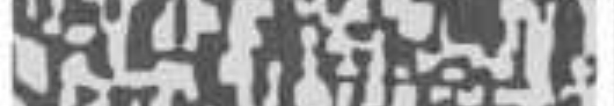

(1)

यदि

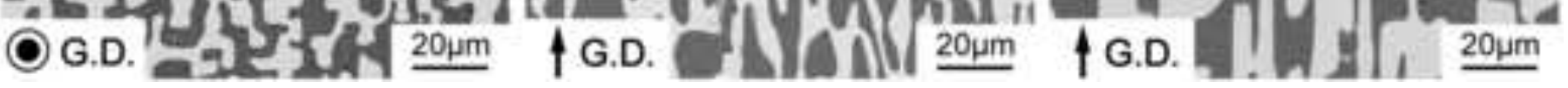



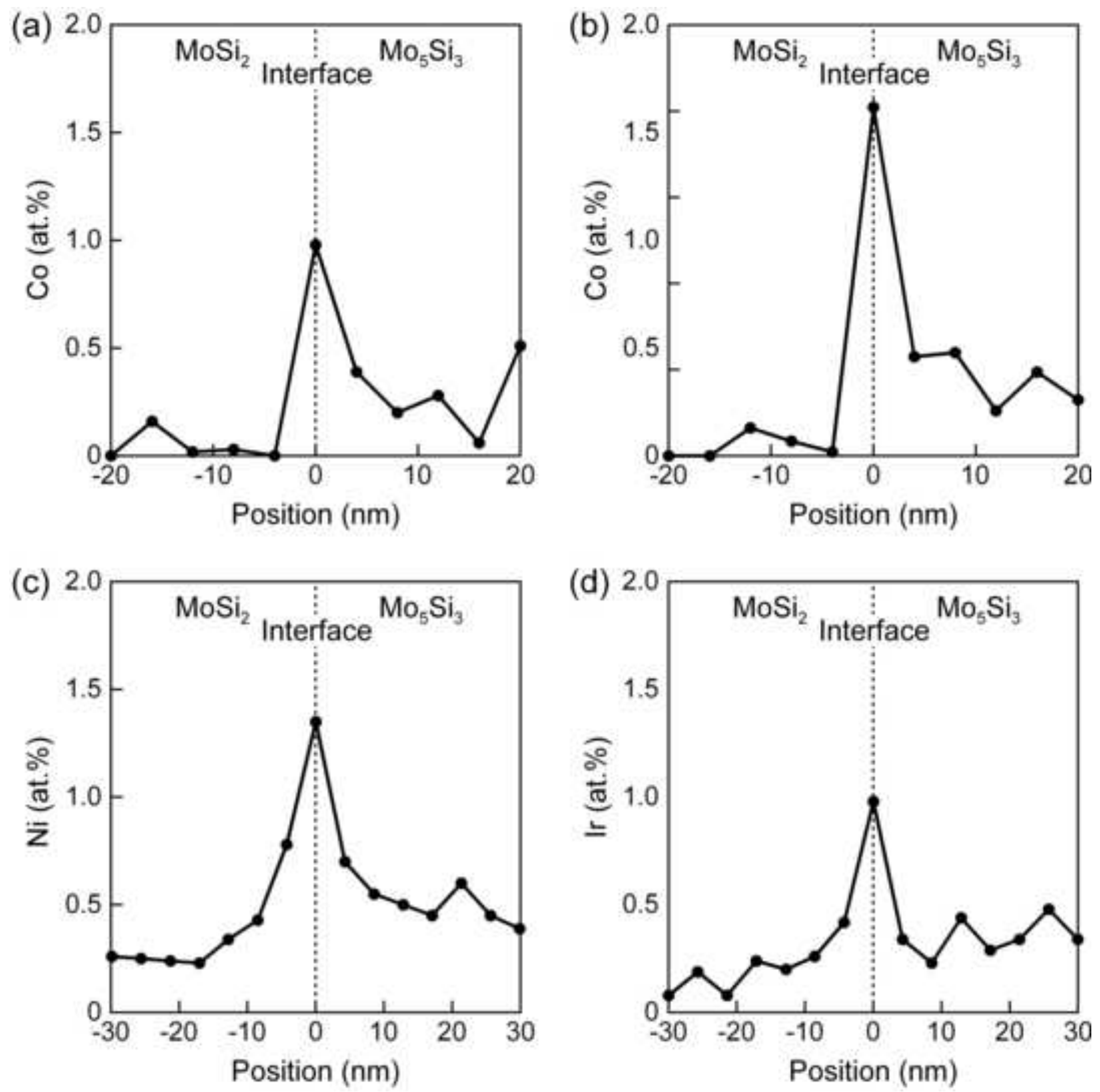


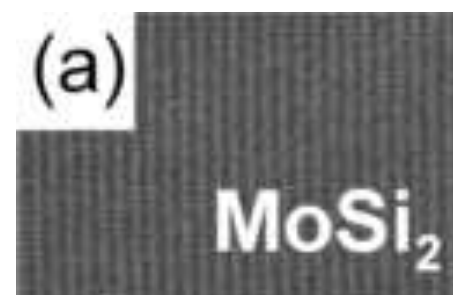

\section{$[1 \overline{1} 0]_{\text {most }}$}

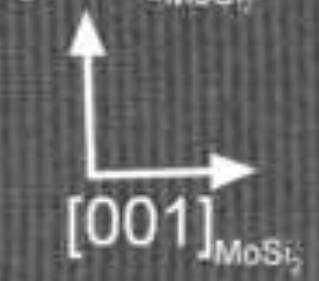

7

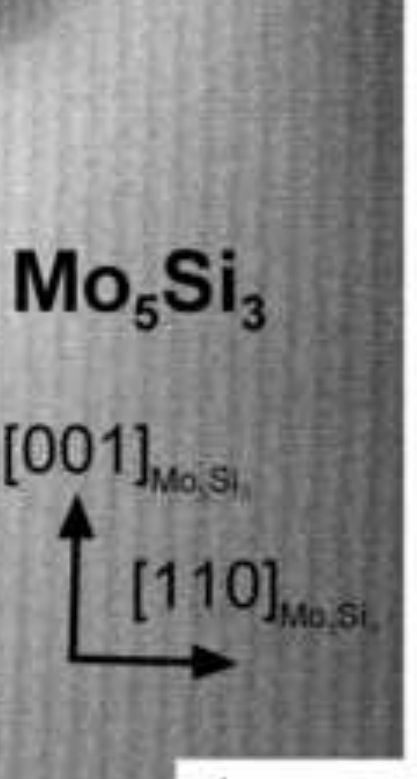

†.D.

$5 \mathrm{~nm}$ (b) $6.0 \quad \mathrm{MoSi}_{2}$ Interface $\mathrm{Mo}_{5} \mathrm{Si}_{3}$

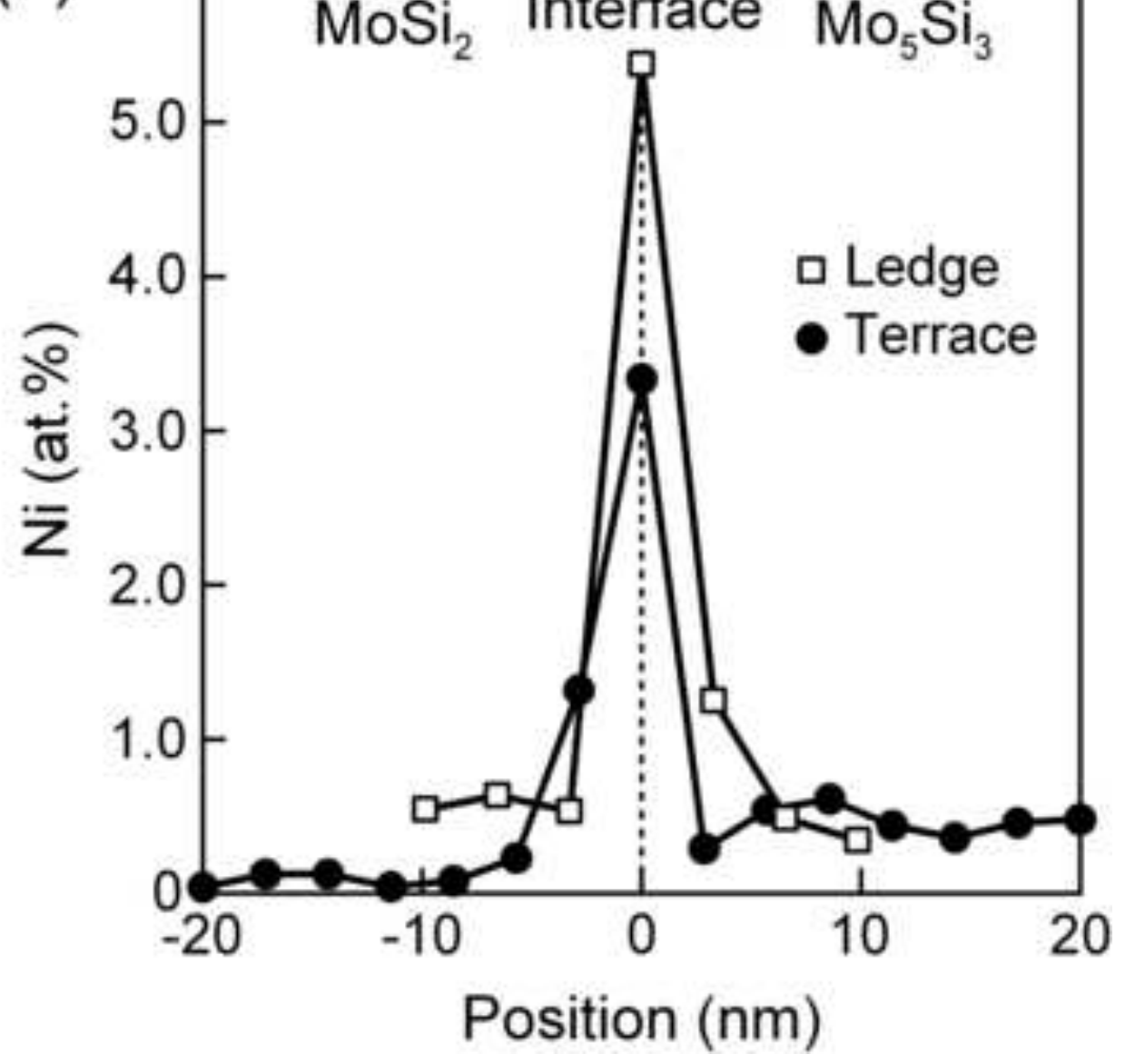




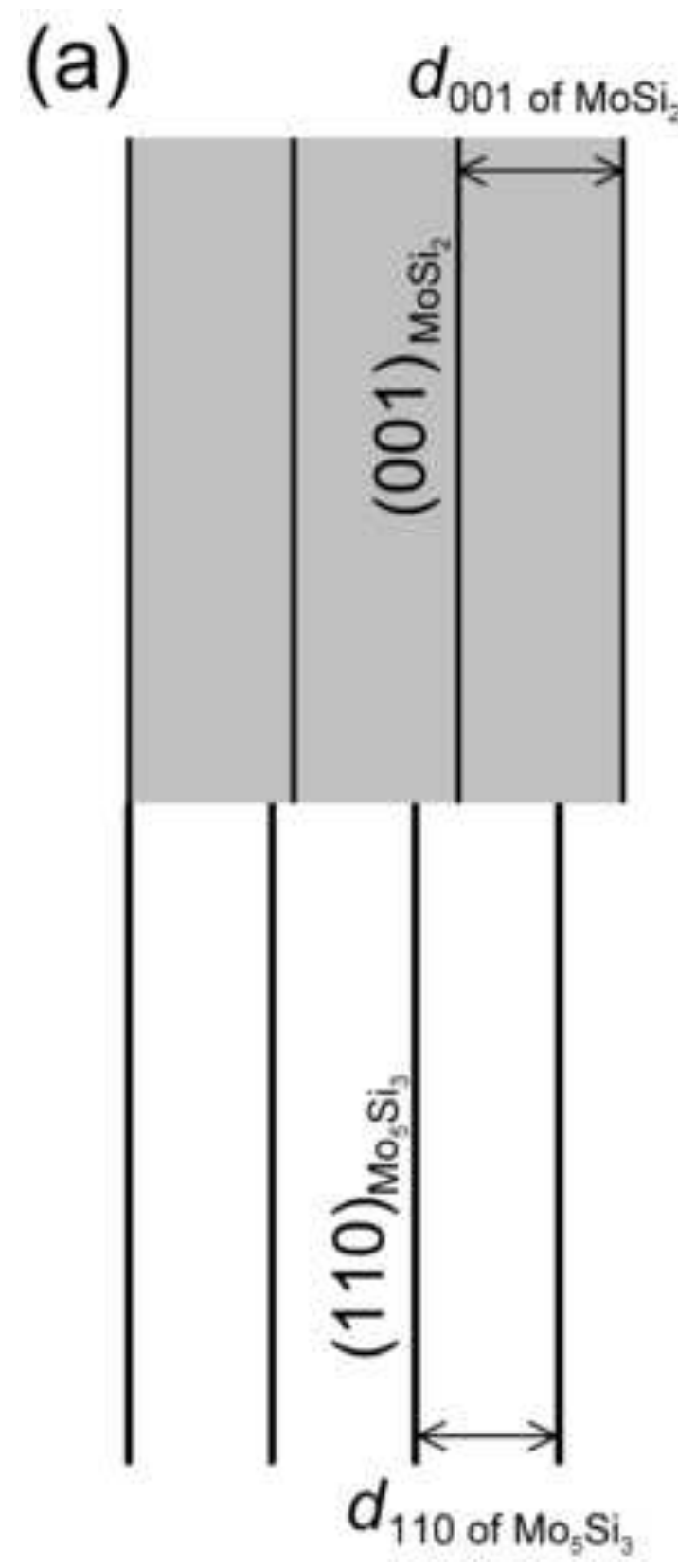

(b) $d_{001 \text { of MoSi, }}$

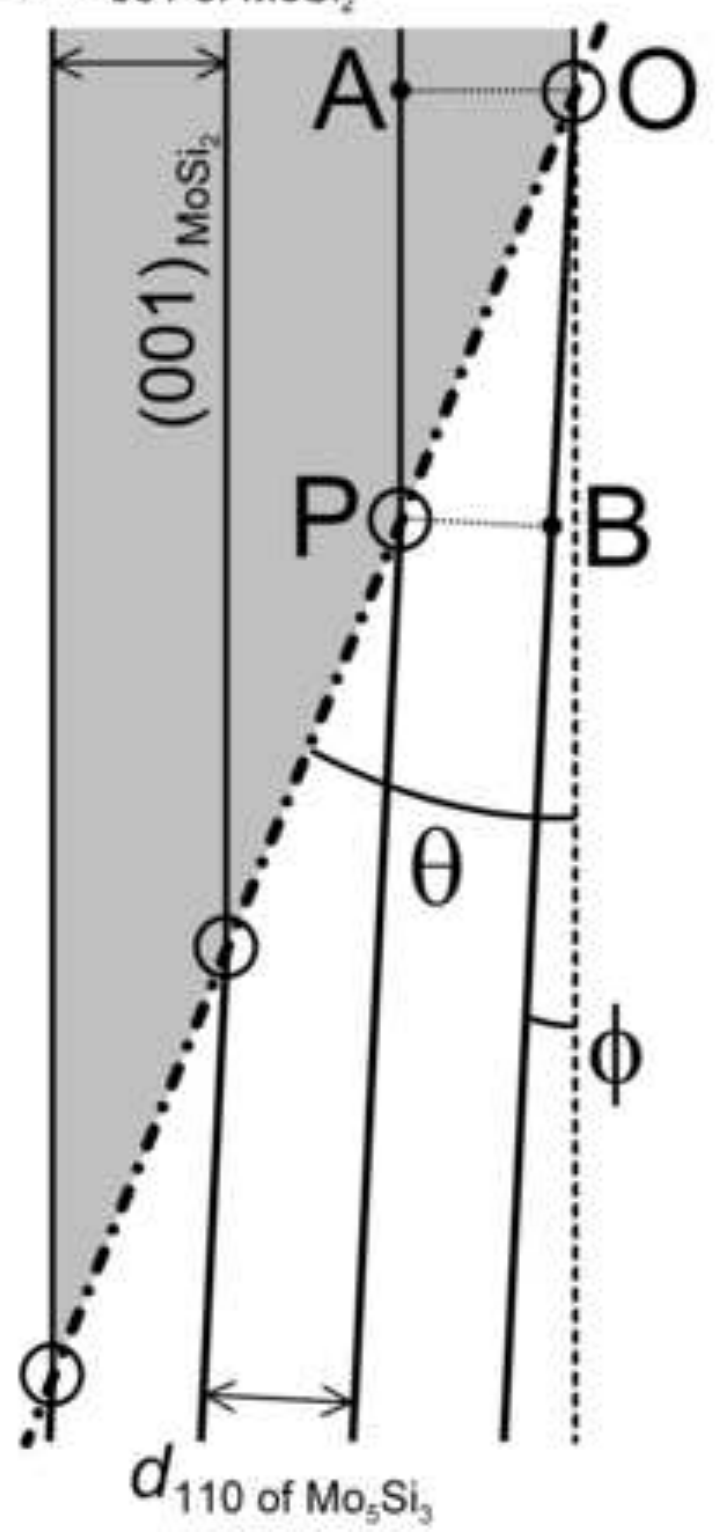

(c) $d_{0011 \text { of } \mathrm{MOSS}_{2}}$

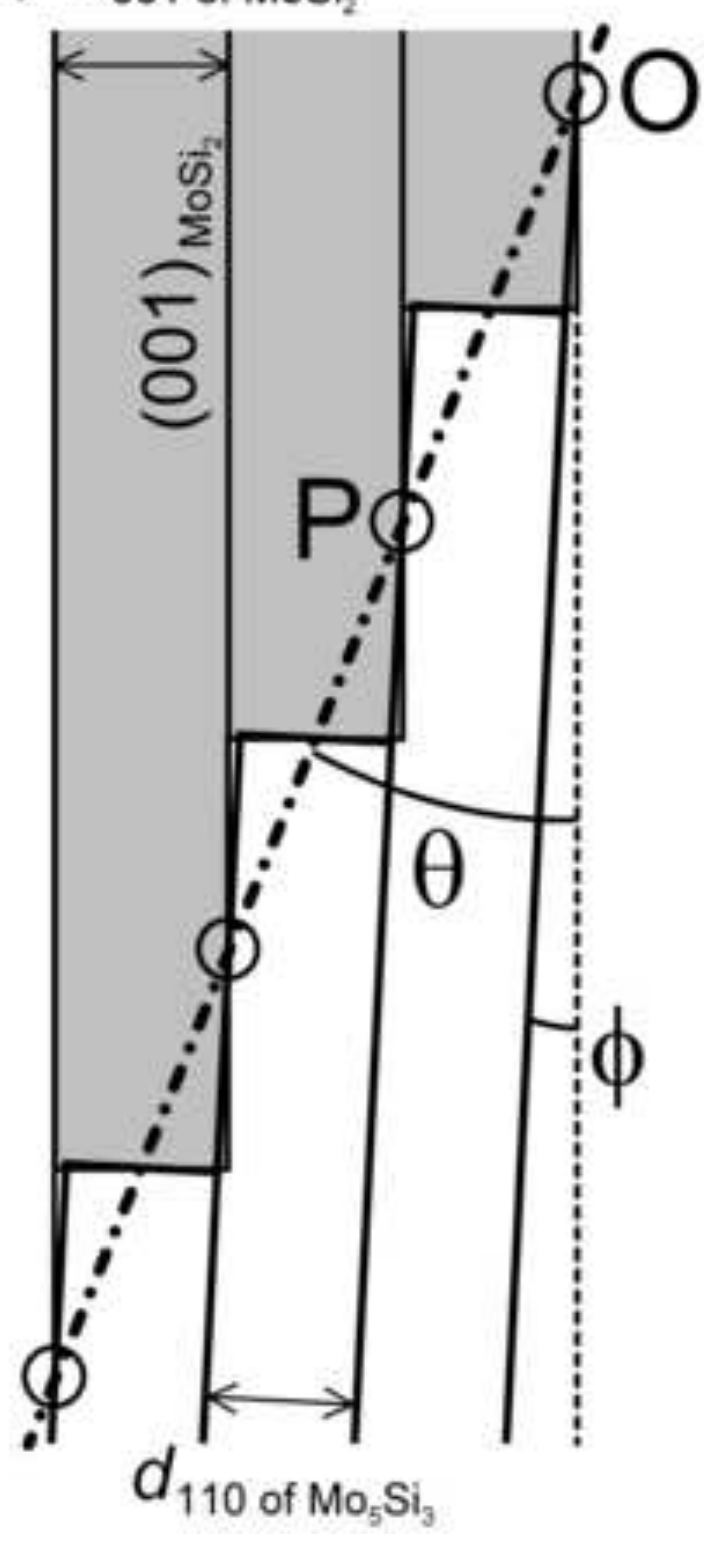




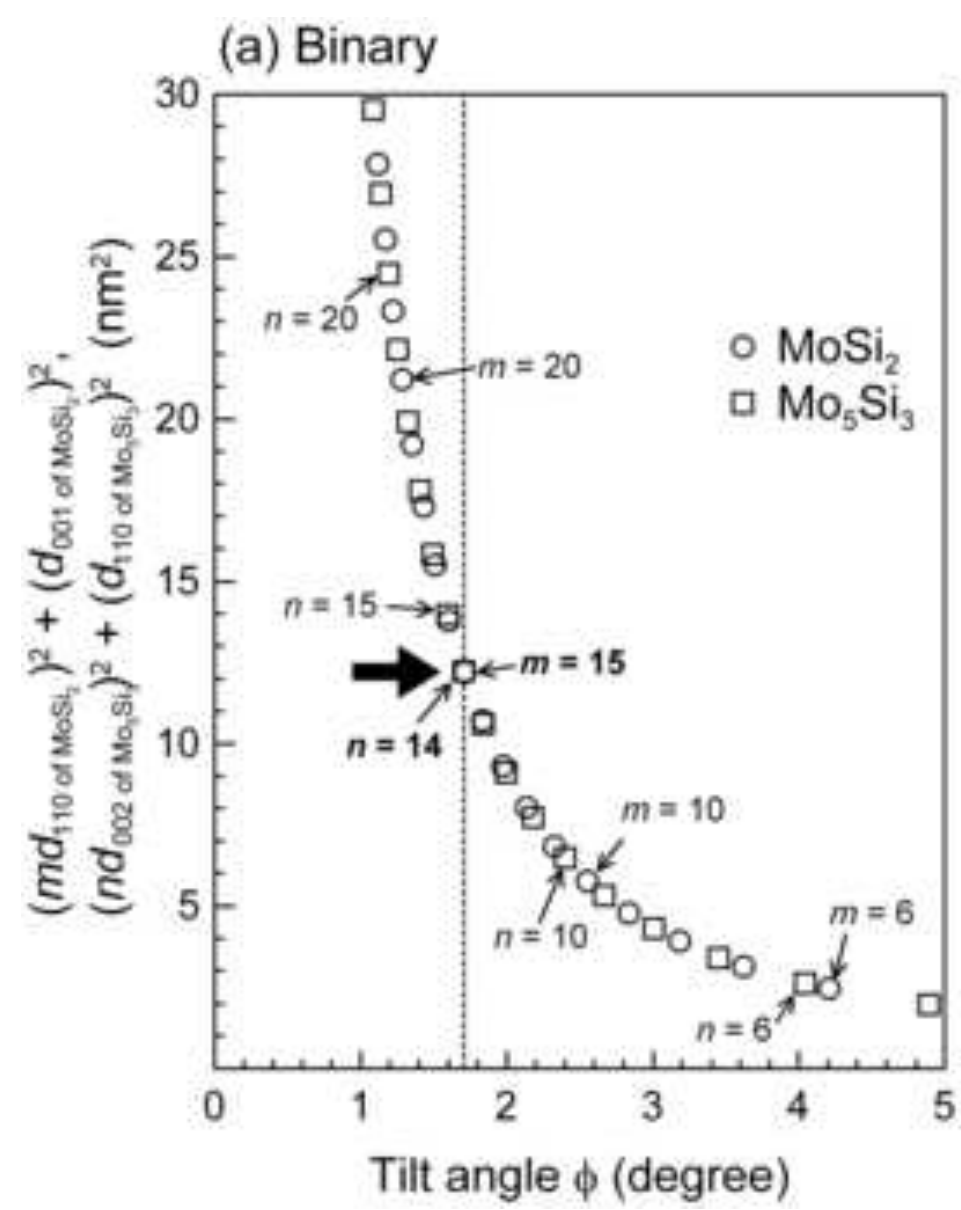

(b) 5 at. $\%$ V alloyed

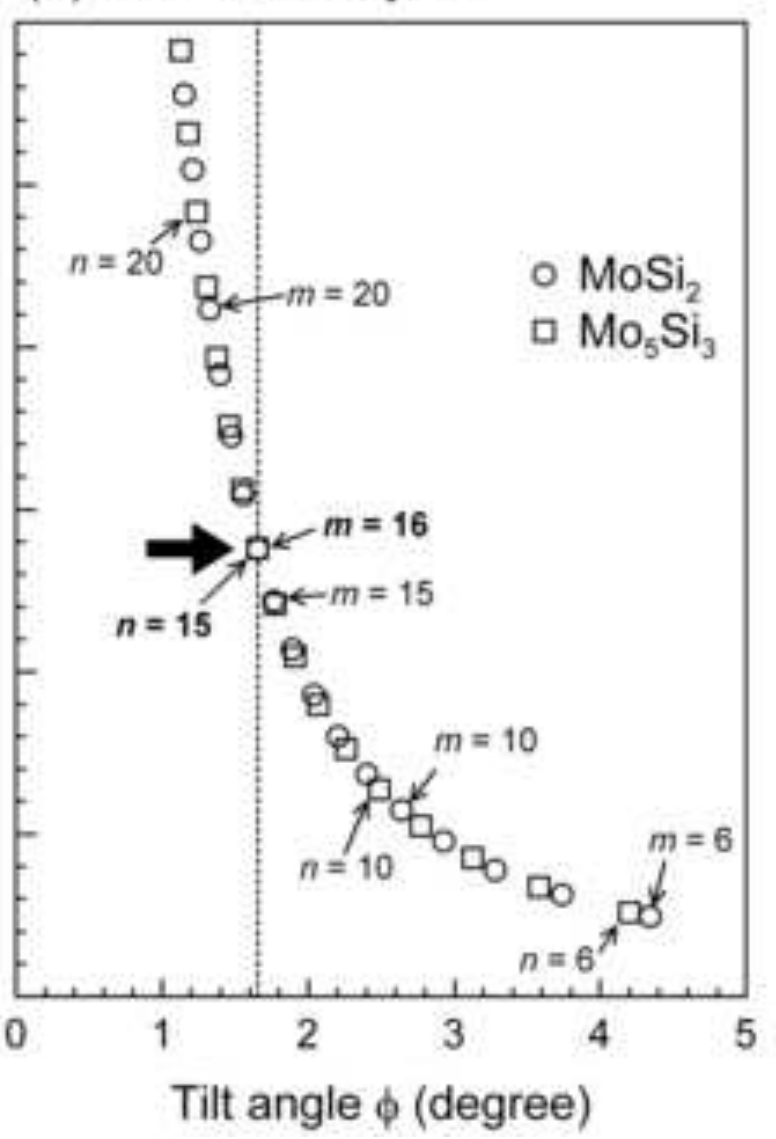

(c) 5 at. $\%$ Ta alloyed

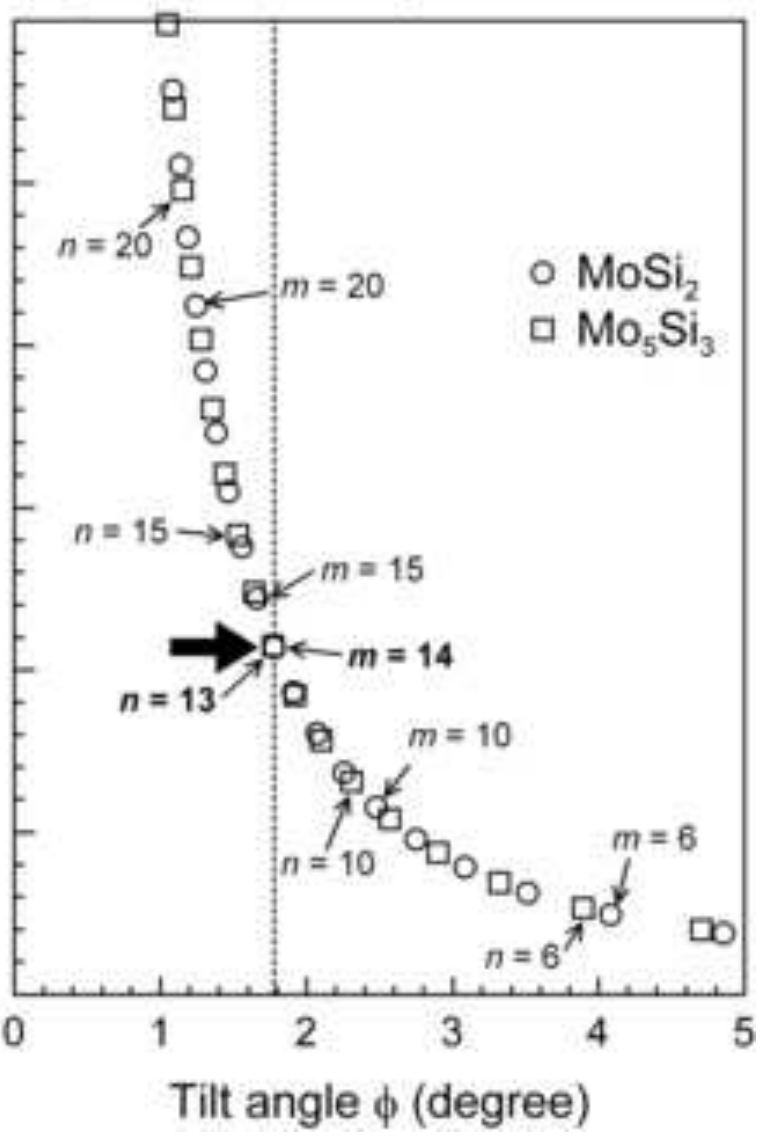

